\title{
Illegal migration and consumption behavior of immigrant
}

\author{
households
}

Christian Dustmann, ${ }^{*}$ Francesco Fasani, ${ }^{\star \star}$ and Biagio Speciale ${ }^{\circ 1}$

\section{March 2016}

\begin{abstract}
We analyze the effect of immigrants' legal status on their consumption behavior using unique survey data that samples both documented and undocumented immigrants. To address the problem of sorting into legal status, we propose two alternative identification strategies as exogenous source of variation for current legal status: First, transitory income shocks in the home country, measured as rainfall shocks at the time of emigration. Second, amnesty quotas that grant legal residence status to undocumented immigrants. Both sources of variation create a strong first stage, and - although very different in nature - lead to similar estimates of the effects of illegal status on consumption, with undocumented immigrants consuming about $40 \%$ less than documented immigrants, conditional on background characteristics. Roughly one quarter of this decrease is explained by undocumented immigrants having lower incomes than documented immigrants. Our findings imply that legalization programs may have a potentially important effect on immigrants' consumption behavior, with consequences for both the source and host countries.
\end{abstract}

JEL classification: F22, D12, K42

Keywords: legal status, weather shocks, consumption behavior.

\footnotetext{
* University College London and Centre for Research and Analysis of Migration (CReAM); ** Queen Mary University of London, CReAM and CEPR; ${ }^{\circ}$ Paris School of Economics - Université Paris 1 Panthéon Sorbonne.

${ }^{1}$ We are grateful to David Bolvin and Carlo Menon for their assistance with the precipitation data, and to Gian Carlo Blangiardo for providing the ISMU survey data. Dustmann acknowledges financial support from the Norface Research Programme on Migration. Fasani acknowledges the financial support of INSIDE-MOVE (Markets, Organizations and Votes in Economics), the Barcelona GSE Research Network, the Government of Catalonia (grant 2009 SGR 896), the JAE-Doc grant for the Program "Junta para la Ampliación de Estudios" co-financed by the European Social Fund and the Spanish Ministry of Science (grant ECO2011-25293). Speciale acknowledges the financial support of the F.R.S.-FNRS (Belgium).
} 


\section{Introduction}

The consumption behavior of immigrants is not only an important subject in its own right, affecting the welfare of what constitutes now a large part of the population in many developed countries, but it also impacts on evaluations of the effects of immigration. Through affecting aggregate demand, immigrants' consumption may influence prices and wages, leading George Borjas (2013) to conclude that "consumption behavior of immigrants is a topic ripe for empirical investigation". ${ }^{2}$ Yet, while impressive progress has been made in many areas in the economics of migration, consumption behavior of immigrants and the way it is affected by immigration policies is surprisingly under-researched.

This paper attempts to fill this void. It is, to the best of our knowledge, the first to investigate immigrants' consumption behavior. Our focus is on one aspect that is in our view particularly important: the way immigrants' consumption responds to their legal status. The share of undocumented immigrants in the overall foreign-born population in developed economies has increased over past decades, ${ }^{3}$ and policies that regulate immigrants' legal status are at the core of the policy debate in many hosting countries. ${ }^{4}$ Legalization gives

2 In line with that, recent work by Dustmann et al. (2015) finds large employment effects of a labor supply shock induced by a commuting policy. One way to reconcile this with findings of smaller employment effects in other works is that consumption induced demand effects are an important component of the immigration impact on local labor markets.

3 This share ranges from about $30 \%$ of the overall immigrant population in the U.S. (or 11.5 million in 2011 , see U.S. Department of Homeland Security, 2012) to $7.5 \%, 4.7 \%, 10.9 \%$, and $15.1 \%$ in the UK, Germany, Spain, and Italy, respectively (HWWI 2009; Fasani 2010a). Estimated yearly inflows are also large: Passel and Cohn (2008) estimate that in 2008 alone, the U.S. received about 500,000 new unauthorized immigrants, while Jandl (2004) estimates that a similar number entered the EU-15 in 2001 alone.

${ }^{4}$ A number of theoretical and empirical papers investigate policies aimed at managing illegal entry of immigrants or legalizing illegal immigrants, see, e.g., Ethier (1986); Chiswick (1988); Hanson and Spilimbergo (1999); Chau (2001); Hanson et al. (2002); Woodland and Yoshida (2006); Hotchkiss and Quispe-Agnoli (2009); Angelucci (2012); Bohn et al. (2014); Facchini and Testa (2014); and Chassamboulli and Peri (2015). See Hanson 
immigrants access to the regular labor market, as well as to tax benefit and health systems, but it may also affect their consumption decisions - which is what this paper concentrates on.

One problem with the study of immigrants' consumption behavior in relation to their legal status is the availability of data that provides reliable measures of both. Our analysis is based on a unique survey of both documented and undocumented immigrants residing in Italy over the 2004-2007 period. One major advantage of this data is the information it includes on consumption of immigrants, broken down by purpose, which is very rare. A unique feature is the reliable construction of measures of legal status the data contains, which makes it particularly suitable for our analysis. ${ }^{5}$ Besides that, Italy provides an ideal context for studying the effects of immigrants' legal status because its immigrant population has intensely increased over the last two decades and unauthorized inflows of immigrants have played a major role in this expansion. Moreover, immigrants arrive from a large and very diverse set of origin countries, and Italy has a quota based system that allows for legalization - both aspects that we will use for our identification strategy. Italy also deports a significant fraction of its illegal population, and deportation efforts vary over time and across regions in a way that individual immigrants are unlikely to foresee - which is another feature that we will use for identification.

We address two important and relevant questions. First, what is the difference in consumption behavior between the populations of immigrants living legally and illegally in the country? Answers to this question are important to assess for instance the impact immigration has on aggregate consumption, or on tax revenue through value added taxes. It should be noted that this comparison includes the effect of endogenous sorting on the composition of

(2006) for a review of the literature on illegal migration from Mexico to the United States, and Orrenius and Zavodny (2005) for analysis on the self-selection among undocumented immigrants from Mexico.

${ }^{5}$ We define undocumented immigrants as immigrants who do not possess a regular residence permit and are therefore not entitled to legally reside and work in the host country. We use the term "undocumented" as a synonym for "unauthorized" and "illegal." 
the two populations. Second, how will an exogenous change in residence status from illegal to legal affect immigrants' consumption behavior? Answers to this question are relevant for e.g. the assessment of the economic impact of legalization programs. While the first question can easily be answered by comparing the two populations in the data, the key methodological problem in addressing the second question is the possible sorting of immigrants into legal status.

We propose two alternative identification strategies to address this issue. Our first strategy is based on the idea that higher levels of rainfall induce a positive and unexpected temporary income shock that allows those who would like to emigrate to cover the cost of an immediate illegal migration (rather than applying for the lengthy legal pathway). Drawing on earlier evidence that shows that weather conditions affect income in developing countries (see, e.g., Wolpin 1982; Paxson 1992; Miguel et al., 2004; Barrios et al., 2010; Brückner and Ciccone 2011; Bazzi 2014) we use weather shocks at the time of emigration as an instrument for legal status. We illustrate that these shocks have a strong effect on income in the emigration countries we consider, and that higher than average levels of rainfall are strong predictors of immigrants' current legal status. We also show that our instrument is orthogonal to immigrants' other characteristics (suggesting that weather shocks do not affect the composition of the immigrant population), and stronger for countries that are more specialized in agriculture (where rainfall variations are important economic shocks), and in countries where households are more likely to face binding financial constraints.

Our second strategy is based on yearly variation in quotas that allowed legalization of resident illegal immigrants and that were introduced in the late 1990s (see Fasani et al., 2013). We construct for each individual in our data a measure of the additional accumulated "exposure" to amnesty quotas, induced by yearly variation away from the predictable trend. Again this instrument is a strong predictor of current legal status. Based on different sources of variation, these alternative IV strategies provide us with two independent possibilities to identify the effect of illegal status on consumption behavior. 
Our results show that legal status has a strong effect on consumption: undocumented immigrants consume about $40 \%$ less than documented immigrants, conditional on background characteristics. Our IV estimates are throughout larger than OLS estimates and remarkably similar across the two alternative IV strategies. About one quarter of the difference in consumption results from undocumented immigrants having lower earnings: conditional on household income, illegal immigrants consume about 30\% less than legal immigrants.

There are different reasons as to why illegal immigrants may consume less (and save more) than legal immigrants, conditional on income. Perhaps most importantly, legal status may reduce future income risk, and therefore the amount of precautionary savings immigrants accumulate. Illegality may also increase the probability that the migration will be terminated prematurely, with migrants facing lower wages and employment probabilities back home, which may lead to intertemporal substitution of leisure and postponement of consumption if leisure and consumption are complements. Further, illegal status may create constraints and costs that prevent individuals from completing certain transactions (e.g., purchasing a registered motor vehicle, sign a contract to rent accommodation, obtain a mortgage) or using formal saving channels (e.g., opening a bank account).

While we do not attempt to distinguish between these various channels, we provide evidence that is consistent with illegal status imposing restrictions on certain types of consumption. We further suggest an alternative estimation strategy based on variation in deportation risk across spatial areas and over time that supports the hypothesis that precautionary motives are one contributing factor in the lower consumption of illegal immigrants.

The existing literature on the relation between legal status and immigrants' labor market outcomes relies predominantly on variation in legal status induced by the 1986 U.S. Immigration Reform and Control Act (see, e.g., Borjas and Tienda 1993; Kossoudji and CobbClark 2002; Amuedo-Dorantes et al. 2007; Amuedo-Dorantes and Mazzolari 2010; see Fasani 
(forthcoming) for a recent review of this literature). ${ }^{6}$ Our paper contributes to this literature by suggesting two novel alternative identification strategies that avoid many of the problems in previous papers that seek to identify the effect of illegality on immigrant outcomes. ${ }^{7}$ In addition, we provide first analysis of the interplay between consumption behavior and legal status and of the various channels along which consumption differs between the two populations.

Our paper also adds to the literature on precautionary savings. ${ }^{8}$ Considering immigrants' legal status as a measure that is strongly correlated with the income risk households face, our analysis addresses the sorting problem that bedevils that literature (see Browning and Lusardi 1996). Our findings are in line with results of Fuchs-Schündeln and Schündeln (2005), who use a methodological approach similar to ours by exploiting differences in income risk between workers in the public and private sectors using German reunification as an exogenous reassignment of sector of employment.

Finally, we extend the use of weather shocks as a source of exogenous variation, a method used by several other authors in different applications to study weather's impact on savings behavior, remittances, network size, migration, health, economic growth, democracy

6 The Immigration Reform and Control Act (IRCA) reformed the United States' immigration law in 1986. It granted amnesty to illegal immigrants who entered the United States before January 1, 1982, and had lived in the U.S. continuously since that time. To the best of our knowledge, only few other papers (Kaushal 2006; Devillanova et al. 2014; Mastrobuoni and Pinotti 2015; Pinotti 2015) study the relation between legal status and behavior based on designs other than the IRCA reform.

${ }^{7}$ Most of the papers in this literature study the IRCA reform using the same longitudinal survey of amnesty applicants (the Legalized Population Survey, LPS) and all face similar limitations. First, using data on applicants for the amnesty only may lead to ignoring endogenous selection into amnesty. Second, there is no obvious control group in the LPS. Third, general equilibrium effects of a program that legalized 2.7 million individuals can confound the estimates. Our strategy is not affected by these issues.

${ }^{8}$ See, for example, Dynan (1993), Hubbard et al. (1995), Gourinchas and Parker (2001) and Fuchs-Schündeln and Schündeln (2005). In the migration literature, Dustmann (1997) develops a model of return migration and precautionary savings, showing that immigrants may have a higher income uncertainty and, therefore, engage in more precautionary savings. 
and/or conflicts (see, among others, Paxson 1992; Munshi 2003; Miguel et al. 2004; Giles and Yoo 2007; Yang and Choi 2007; Deschênes and Moretti 2009; Maccini and Yang 2009; Barrios et al. 2010; Brückner 2010; Feng et al. 2010; Pugatch and Yang 2010; Brückner and Ciccone 2011; Ciccone 2011; Dell et al. 2012; Bazzi 2014). We add to this literature by demonstrating that temporary weather shocks are also a powerful predictor of immigrants' legal status.

The paper is organized as follows. Section 2 addresses the relation between legal status and immigrant's consumption, discusses endogenous selection into legal status, and explains our empirical strategy and instrumental variable approach. Section 3 provides relevant background information on immigration to Italy and introduces our data. Section 4 reports our empirical results. Finally, Section 5 discusses our findings and concludes the paper.

\section{Consumption and IIlegal Status}

Our analysis focuses on immigrants' consumption in the host country, and how it varies with legal status. There are several reasons why illegal immigrants may have a different consumption behavior than documented immigrants. Lacking legal status generally implies being exposed to higher uncertainty about current and future earnings and may thus lead to more savings for precautionary motives. Illegal status may also lead to inter-temporal substitution of leisure: As an illegal migration may be terminated early through detection and deportation, ${ }^{9}$ and low wages and employment opportunities at home could lead to intertemporal substitution of leisure, so that leisure-consumption complementarities may lead to lower consumption today (as in Heckman and MaCurdy 1980). Further, illegal status may impose barriers to, and costs on consumption that prevent individuals from making specific purchases (e.g., a registered motor vehicle or registered housing). All these channels point at

\footnotetext{
${ }^{9}$ Over the period 2004-2007, the probability of deportation was 5\% per year in Italy. In comparison, over the same period this probability was close to zero in the U.S. (see Fasani 2010a, 2010b for Italy; Goyle and Jaeger 2005 for the U.S.).
} 
lower consumption of illegal immigrants in the host country (conditional on income). In addition, consumption could be indirectly affected through the impact legal status has on employment opportunities and earnings (see, e.g., Borjas and Tienda 1993; Kossoudji and Cobb-Clark 2002; Kaushal 2006; Amuedo-Dorantes et al. 2007). In our analysis we will not attempt to distinguish between these different mechanisms, which is beyond the possibilities of the data we have available. We will however provide further evidence that precautionary motives are likely to be one important reason as to why illegal immigrants consume less than legal immigrants.

We will also refrain from investigating savings and remittances, due to both conceptual issues and data limitations. ${ }^{10}$ Total savings consist of savings held in Italy as well as in the home country, and we have no measure of the latter. Dustmann and Mestres (2010) show that failing to take into account savings accumulated in the home country may severely distort any conclusion on immigrants' saving behavior. Remittances, instead, are a composite of different transfers, with an overall ambiguous relationship to illegal status, including moneys used to finance consumption of family members in the home country, to accumulate savings at home, to invest into durable consumption- or investment goods, or to support the wider village community (as insurance for a future return and re-integration). Further, our survey asks migrants to report the average amount they send home each month. This measure may systematically mis-measure remittances if transfers are less frequent, and if transfer frequency differs by legal status (e.g. because illegal migrants have no access to official banking channels). Documented migrants may, moreover, travel back home more frequently than undocumented migrants and carry money with them in addition to (or rather than) sending

${ }^{10}$ Consumption can be written as the difference between income earned in the host country $Y$, savings $S$ and income transferred back to the source country (or remittances) $R: C=Y-S-R$. 
remittances. For all these reasons we do not believe that our measures of savings and remittances can be related to legal status in a meaningful way.

In contrast, consumption in the host country is well measured in our data (see Section 3). It is an outcome that can be directly linked to individuals' optimizing behavior and parameter estimates have therefore a clear interpretation. Furthermore, our consumption measure is related to a precise reference period, as respondents are asked about the average monthly expenditure of their household in Italy for different groups of consumption items.

In our empirical analysis, we therefore estimate the following model:

$$
C_{i t}=\alpha+\beta I_{i t}+X_{i t}^{\prime} \gamma+f_{c}+d_{t}+\epsilon_{i t}
$$

where $i$ is an index for the individual migrant, $c$ is the country of origin, and $t$ is the year of interview. The dependent variable $C_{i t}$ is the log of i's monthly consumption in the host country, and $I_{i t}$ is a dummy variable equal to 1 if the immigrant has illegal status. The vector $X_{i t}$ includes individual controls of the respondent (gender, age, age squared, education level, years since arrival, dummies for province of residence) and household characteristics (number of household members living in Italy, a dummy for spouse living abroad, number of children living in Italy and abroad, dummies for type of accommodation in the destination country). In Table 1, we provide detailed descriptive statistics for these variables. Country of origin fixed effects and year of interview dummies are denoted as $f_{c}$ and $d_{t}$ respectively, and $\epsilon_{i t}$ is an error term. The parameter of interest is $\beta$.

\subsection{Identification}

Estimation of (1) using OLS generates an estimate $\beta$ that measures the (conditional) difference in consumption between legal and illegal immigrants who are living in Italy. It combines the causal effect of legal status on consumption, and the effect through sorting of immigrants into legal status. This composite parameter, although not causal, is nevertheless important for policy when determining e.g. the difference in fiscal contributions, or the differences in aggregate demand of the existing populations of legal and illegal immigrants. 
However, if interest focuses on the causal effect on consumption by exogenously changing migrants' legal status (e.g. to inform policy about the effect of implementing legalization programs), one needs to eliminate the effect of sorting into legality. One such likely source for sorting may be risk aversion. If immigrants who enter the country illegally are less risk averse than those who enter legally, and if less risk averse individuals save less, then our estimate of $\beta$ is biased toward zero (see Dynan 1993 for a discussion of this bias). ${ }^{11}$ To address this, we suggest two alternative estimation strategies, based on instruments that affect legal status at two different stages: At the point when the migration decision is taken, and after having arrived in Italy as an illegal migrant. ${ }^{12}$

More specifically, consider the current residence status $I_{i t}$ of migrant $i$ at time $t$ that is determined by status at entry (legal versus illegal) in period $t_{0}, I_{i t_{0}}$, and opportunities of obtaining legal status after arrival (between $t_{0}$ and $\left.t\right), L_{i t-t_{0}}$, as well as individual unobserved characteristics $\mu_{i}$ :

$$
I_{i t}=f\left(I_{i t_{0}}, L_{i t-t_{0}}, \mu_{i}\right)
$$

Our identification strategy relies on plausibly exogenous variation that varies either $I_{i t_{0}}$ or $L_{i t-t_{0}}$. To vary $I_{i t_{0}}$, we use shocks to income in the home country before emigration as exogenous determinant of the initial decision of migrating legally or illegally. To vary $L_{i t-t_{0}}$, we employ variation in the opportunities for legalization in the host country that arise for each immigrant after emigration and that is induced by accumulated yearly differences in

11 This case is similar to the problem of selection into self-employment (Skinner 1988; Guiso et al. 2002) or public sector employment (Fuchs-Schündeln and Schündeln 2005): more risk averse workers may select into occupations and sectors that imply lower income uncertainty. In that context, as in our case, occupational/sector choice is endogenous, and failing to control for selection leads to a systematic underestimation of the importance of reducing consumption for precautionary reasons.

${ }^{12}$ Another issue in measuring behavior of immigrants is selective return migration (see Dustmann and Gorlach (forthcoming) for discussion). In our data, there is no significant difference in return intentions between documented and undocumented immigrants (results can be provided upon request). 
legalization quotas from a predictable trend. We now discuss these two strategies in more detail.

\subsection{Rainfall and Income Shocks}

Individuals have two possibilities to migrate to Italy: Either legally, through a visa application, or illegally. While the first option implies long waiting times, and may well be unsuccessful in the end, the second option is immediate, but rather costly, so that credit constrained individuals may be restrained from migrating through this route. ${ }^{13} \mathrm{~A}$ positive temporary income shock may alleviate credit constraints of those who would want to emigrate but would rather avoid the long and potentially unsuccessful legal route in favor for the illegal route, ${ }^{14}$ by being able to afford an immediate illegal migration. If the destination country, moreover, offers possibilities to obtain legal status after arrival, opting initially for an illegal migration can be an effective, though more expensive, way of speeding up the process of becoming a legal resident.

We use here rainfall shocks at the time of emigration as a temporary shock to income that may potentially trigger an illegal migration and predict current residence status through the persistence in legal status over time. The rationale for our instrument is that rainfall generates income shocks by affecting agricultural production, thereby temporarily relaxing the liquidity constraints that restrict migration. Most of the source countries included in our sample

13 Illegal migration implies far higher monetary costs as migrants have to compensate smugglers, buy forged documents, pay border officials at home and abroad, etc. Existing evidence illustrates that the price paid by undocumented migrants is substantially higher than the simple cost of the trip (see, e.g., Friebel and Guriev 2006; Gathmann 2008; The Economist 2012). Recent UNODC data, for instance, show that the price for being smuggled into the U.S. from Central America in 2009 was about $\$ 3.5$ thousand for Central Americans, $\$ 7-7.5$ thousand for Africans and Indians and \$45 thousand for Chinese (UNODC 2012).

${ }^{14}$ Note that this will not affect potential migrants who already secured a legal entry to the destination country. 
are highly dependent on agricultural production. ${ }^{15}$ Therefore, shocks to that sector are likely to have an important impact on the livelihoods of large parts of the population, either directly (by individuals working in that sector), or indirectly (by affecting sectors related to agriculture, such as retail). Further, as rainfall shocks are transitory, and uncorrelated over time, they should not affect permanent income, and therefore the more fundamental decision whether or not to emigrate. As a consequence, they should not affect the overall population of potential migrants - something we test in our empirical section.

We measure rainfall shocks using data from the NASA Global Precipitation Climatology Project (see Adler et al. 2003), which provides monthly mean rainfall data on a $2.5^{\circ} \times 2.5^{\circ}$ latitude-longitude grid from 1979 onwards. Based on these data, we first compute the yearly rainfall averages for each country of origin for the immigrants in our sample. We then match each individual with the average yearly rainfall in the year of emigration (and in the previous year) in the country of origin. As we condition on country fixed effects, which removes the country-specific mean of rainfall, our rainfall measure is equivalent to using rainfall deviations from the country mean and can be interpreted as a temporary "shock" to precipitation in the home country in the period preceding migration.

We show below that rainfall in the year, and the year previous to emigration is indeed a strong predictor of current legal status. We further demonstrate that our instrument is stronger in countries with a larger agricultural sector and where the households are more likely to be cash-in-advance constrained. Moreover, based on World Bank data on agricultural and total income for a panel of almost 100 developing countries over the period 1979-2012 which we

${ }^{15}$ Almost all the origin countries of immigrants residing in Italy are low and middle-income nations that are highly dependent on the agricultural sector. According to World Bank data, over the 1995-2007 period, the sampleweighted average share of agricultural employment for the 20 countries in our sample with the largest number of immigrants (which accounts for $81 \%$ of our overall sample) is almost $41 \%$, while the average share of agriculture on GDP is about $19 \%$ (see Appendix Table A.1 for details). These numbers are roughly 10 times larger than the OECD average (4\% and $2 \%$, respectively) and 6-8 times larger than those for Italy ( $5 \%$ and $3 \%$, respectively). 
match to the GPCP data on rainfalls, we show that rainfall shocks have a strong impact on per capita (agricultural) income.

\subsection{Legalization quotas}

Our second identification strategy relies on the accumulated exposure of immigrants to deviations of yearly quotas to grant legal residence after their arrival in Italy.

In the late 1990s, Italy adopted a quota system that was meant to regulate the entry of migrant workers to the Italian labor market. Since its introduction, however, the system has been widely used to grant legal status to undocumented immigrants who reside in Italy (Fasani et al. 2013; Pinotti 2015), as the Italian authorities are unable to discriminate between applicants who apply from abroad, and who live unlawfully in Italy. At the end of each year, the government issues a "flows decree" that establishes the number of immigrants that will be allowed to enter the country in the following year for work reasons. The government should choose the size of the quota - which can also be set to zero - based on forecasts of labor market shortages and demand for foreign workers as well as availability of public and social services at the local level (housing, schools, health services, etc.). Once the quotas are set, a date is announced for employers to start filing applications to sponsor an immigrant. Residence permits are then allocated to valid applications, in order of application receipt and until the quota is reached. Quotas are usually lower than the number of applications filed. This rationing of residence permits, in conjunction with unforeseen differences from year to year in the number of total permits, generates randomness in granting legal status, as is well documented in Pinotti (2015). As Appendix Table A.3 shows, quotas started in the late '90s at about 20 thousand working permits per year, increased gradually to almost 90 thousand in 2001 and decreased to 80 thousand in 2002-2004, only to increase again in 2005, reaching a 
peak of 550 thousand in 2006 and then dropping to 250 thousand in $2007 .{ }^{16}$ Besides "general" quotas, open to immigrants of any origin, there were also country-specific quotas, allocated only to immigrants from certain origin countries. As Appendix Table A.3 shows, over the period considered, three nationalities (Albania, Morocco and Tunisia) were the primary beneficiaries of these country-specific quotas. As for total quotas, these national-reserved quotas experienced substantial fluctuations over the period 1996-2007.

The underlying rationale for the instrument is that immigrants who were "exposed" to larger quotas, and had the possibility to apply for legalization schemes over a longer period, should be more likely to have acquired legal status. The identifying assumption is that quotas set by the Italian government are orthogonal to migrants' individual characteristics and affect their consumption decisions only via the impact on immigrants' legal status. To implement this strategy, we therefore match each migrant in our sample with the total number of residence permits offered through the quota system since arrival in Italy. More specifically, for each immigrant, we compute the overall exposure to general residence permits offered by Italy to which the individual has been exposed since arrival, $Q_{i t}=\sum_{t=t_{i 0}}^{T-1} q_{t}$, where $t_{i 0}$ is the arrival year of individual $i, T-1$ is year before the interview, and $q_{t}$ is the quota of residence permits offered in year $t .{ }^{17}$ We do not include in the summation the quota offered in the interview year $T$ because it cannot affect the migrant's legal status. ${ }^{18}$ Note that the total number of quotas an individual is exposed to until interview differs for individuals who arrived at different dates, as there is variation in the quotas over time. We illustrate that in Appendix Figure A.1, which

16 In 2006, the Italian government initially set a quota of 170 thousand working permits but, once the applications had been submitted, decided to legalize all valid applicants. Such a decision was unexpected and unprecedented and it was never repeated in following years.

${ }^{17}$ We discuss only the case of residence permits to which individuals from every country can apply. Extensions to country specific permits are obvious.

${ }^{18}$ The ISMU survey interviews take place in the spring of each year, while quotas are set and announced at different dates each year. Furthermore, several months elapse between the beginning of the application window and the actual granting of residence permits to successful applicants. 
carries the log of total quotas on the vertical axis, and the year of arrival on the horizontal axis, and where points are connected for total exposures to quotas for each of the four interview years. Comparing points vertically in this figure refers to individuals of the same arrival cohort who were interviewed in different years and thus exposed to different quotas. Comparing points along upward sloping diagonals across lines refers to individuals with the same residence in Italy, but who arrived in different years, and were therefore exposed to different quotas. The connected lines decline over time because migrants who arrived later in Italy had fewer opportunities to be legalized.

In our empirical strategy, we address the (unlikely) possibility that individuals are able to predict future quotas in Italy. We assume that any such predictions are "rational" in the sense that they can be expressed as linear projections of the implemented quotas to which an individual is exposed to after arrival. We then use only the accumulated deviations of yearly quotas from these expectations for identification. This amounts to using the residual of the following regressions as an instrument:

$$
\ln Q_{i t}=a_{0}+a_{1}\left(t-t_{i 0}\right)+d_{t}+\omega_{i t}
$$

where $\ln Q_{i t}$ is the (log of) total numbers of working and residence permits offered by the Italian government since arrival date $t_{i 0}$ of migrant $i, t-t_{i 0}$ is the total number of years the immigrant has resided in Italy, and $d_{t}$ are dummies for the interview year. The predicted residual $\widehat{\omega}_{i t}$ is our instrument. We illustrate the residual variation that we use for identification in Appendix Figure A.2.

To test the robustness of this identification strategy we also use two alternative instrumental variable approaches. First, we assume that migrants have "adaptive" expectations, in the sense that they predict future quotas after their arrival based on past quotas observed up to the point of immigration. In particular, we assume that a migrant arriving in Italy in year $t_{i 0}$ expects the quota for that year and the following years to be equal to the average quota observed until the year before migration. Our instrument is then the difference between the actual cumulative quotas and the expected cumulative quotas, and captures the 
deviations in the policy from what the migrant has predicted before migrating, based on observed past realizations of yearly quotas. Second, we exploit the heterogeneity across nationalities in quotas and match citizens of the three main "privileged" countries to their country-specific quotas, while all other immigrants are matched to the overall quotas (net of national-reserved quotas). ${ }^{19}$ We maintain the assumption of "rational" expectations of future quotas and use as instruments the residuals from separately estimating equation (2) for each of the three privileged countries and for all the remaining countries pooled together. In our estimations, all these strategies lead to similar results. We report therefore results using $\widehat{\omega}_{i t}$ as our main instrument, and results using the alternative instruments as robustness checks.

\subsection{Parameter interpretation}

The two instruments we propose - rainfall shocks in origin countries before migration and unexpected legalization opportunities in Italy after migration - rely on entirely different variation. They also identify two potentially different local causal parameters. Weather shocks, by relaxing the budget constraint, identify a LATE effect of a population of "compliers" (those who would have liked to emigrate legally but who were induced by a positive income shock to choose the immediate illegal option). ${ }^{20}$ The quota instrument, by randomizing illegal immigrants who are already residing in Italy into the pool of legal immigrants, identifies a "local" effect for illegal "compliers" who have been exposed to legalization opportunities measured

${ }^{19}$ Over the period 1996-2007, the Italian government granted two general amnesties (in 1998 and 2002) that provided opportunities for legalization in addition to the quota system we have just described. We do not exploit this additional source of exogenous variation in legal status because the instrument one could construct using these amnesties (i.e. having arrived in Italy before 1998 or before 2002) is mechanically correlated with the duration of residence in Italy (a control always included in our regressions).

${ }^{20}$ In Appendix Section A2.1, we discuss the potential bias implied by using rainfall shocks as instrument for legal status. In particular, we show that if positive shocks affect the overall pool of potential migrants, the IV estimator will identify a lower bound (in absolute value) of the effect of being undocumented on immigrant consumption. 
as the accumulated deviations from the trend of issued residence permits since year of arrival in Italy. The two estimated parameters can, but do not need to be the same.

\subsection{Household Income}

While equation (1) is our main specification, it may also be of interest to determine how illegal status affects consumption conditional on income. Our measure of income refers to overall household income, which consists of various components, as we explain below (Section 3). As for consumption, we use this measure by apportioning to individuals their share of household income using an equivalence scale (see Section 3.1). One potential concern is that this measure is potentially correlated with unobservables that affect also consumption. For instance, as household income includes the household's total hours of work, it may well be that hours of work are correlated with unobservables that also affect consumption, or that unobserved components that affect underlying wages are also correlated with consumption. If income and legal status are correlated, any bias in estimates of the coefficient on income will also affect the estimate of the impact of legal status on consumption. ${ }^{21}$

To address these potential concerns, we would need an additional instrument for immigrants' income. Since immigrants' earnings are highly responsive to economic conditions (Dustmann et al. 2010), one possibility is to exploit the exogenous variation in labor market conditions across different provinces of residence and over time. In particular, we match each immigrant to the unemployment rate in the province of residence in the interview year and use this variable to instrument individual income (see Section 4.2.2). The exclusion restriction assumes that changes in local unemployment rates affect immigrants' consumption only through disposable income.

\section{Background, Data and Descriptives}

\footnotetext{
${ }^{21}$ Mismeasurement of monthly income is another concern.
} 
After Italy became a net immigration country in the late 1970s, its immigrant population initially remained smaller than that of other European countries, with an immigrant share of $1 \%$ still in the late 1980s (Del Boca and Venturini 2003). From the early 1990s onwards, however, immigrant inflows increased dramatically, with much of it being undocumented. Between 1986 and 2002, different Italian governments granted five general amnesties that legalized almost 1.5 million unauthorized immigrants. As discussed in Section 2.3, a quota system was adopted in the late ' 90 s to regulate the legal entry of foreign-born workers. Over the years, family reunification entries had also increased greatly. By 2008, the number of legal resident immigrants was about 3.7 million or $6 \%$ of the total population. In the same year, the undocumented immigrant population was around 650,000 or about $15 \%$ of the foreign-born population (Fasani 2010a). Many of these illegal immigrants find employment in Italy's large shadow economy, which in 2003 accounted for about $26 \%$ of the official GDP, compared with an average $16 \%$ and $9 \%$ for the OECD and U.S., respectively (Schneider 2005).

Being an unauthorized immigrant in Italy implies daily exposure to substantial uncertainty, which may have effects on precautionary savings, being one factor that explains the lower consumption of illegal immigrants. By law, all citizens are required to carry the official Italian ID with them at all times, while immigrants must always carry their passport and the documents proving the legitimacy of their residence in the country. Italy is an ethnically homogenous country where immigrants can be easily recognized by officers who inspect individuals routinely and apply racial profiling in doing so. ${ }^{22}$ The lack of a residence permit prevents immigrants from having a legal working contract, accessing the welfare system (apart from emergency care), or signing a house rental contract and confines them to employment in the informal sector. Moreover, the probability of apprehension and removal of undocumented immigrants is high. Over the 2004-2007 period, the time span covered by our data, the average estimated population of undocumented immigrants was around 600

22 During the period under study (2004-2007), the Italian police report having checked and identified about 79 million individuals each year, a very large number for a country that has about 59 million residents. 
thousand, with more than 90 thousand arrested and 26.4 thousand subsequently deported each year (Fasani 2010a, 2010b). These figures imply an overall probability of apprehension and deportation of $14 \%$ and $5 \%$ per year, respectively. For comparison, over the same period, U.S. resident undocumented immigrants faced a $2 \%$ probability of being apprehended and a negligible probability of removal (see Goyle and Jaeger 2005).

\subsection{Data and Descriptive Evidence}

Our analysis is based on a large and representative sample of both documented and undocumented immigrants residing in Italy's Lombardy region. Data are taken from an annual survey run by the Institute for Multiethnic Studies (ISMU). This survey was launched in 2001 and administered to around 8,000 immigrants in each wave. Since 2004, it has included items on household expenditure, savings, and remittances. For this analysis, we pool four survey waves (2004-2007) to obtain a sample of 13,672 observations representing over 100 different nationalities (Appendix Table A.1). ${ }^{23}$ Of the overall sample, 11,865 individuals are documented immigrants and 1,807 are undocumented (Table 1). The data, which are detailed in Appendix Section A.1, contain information on both the interviewee (e.g., gender, age, employment status) and the household (e.g., number of members, accommodation, income, consumption).

${ }^{23}$ We eliminate from our sample all immigrants who are nationals of one of the New Member States (NMS) that joined the European Union in 2004. Although Italy adopted transitional period restrictions that prevented NMS nationals from legally working in the Italian labor market, these immigrants immediately acquired the status of European citizens and the right of legal residency. Further, we restricted the sample to individuals with at most 10 years of residence in Italy to ensure common support between documented and undocumented immigrants (since the latter group has substantially shorter average residence duration than the former; see Table 1). In Appendix Table A.7, we show that our findings are very similar when the threshold varies from at most 5 to at most 15 years of residence in Italy (see Section 4.2.1). 
The ISMU survey is specifically designed to elicit truthful reporting of legal status. ${ }^{24} \mathrm{We}$ construct three definitions of undocumented immigrants. The most restrictive definition assigns the label "undocumented" only to those who reported not having a residence permit. A second definition also covers those who reported having applied for amnesty but had not yet received a response ( $1 \%$ of our sample). A third definition includes also all those who reported being currently in the process of renewing their residence permit ( $5 \%$ of our sample), which implies that they may not have had legal status at the time of interview. Based on these alternative definitions, the share of undocumented immigrants in the estimation sample is $12 \%, 13 \%$, and $18 \%$ respectively (see Appendix Table A.2). Throughout this paper, unless otherwise noted, we use the second definition; however, we show that our results are not sensitive to the definition adopted (see Section 4).

Table 1 provides summary statistics on individual and household characteristics for the two groups. Undocumented immigrants are slightly younger than documented immigrants, with a mean age of 31.6 (versus 33.3) years. Both groups have similar levels of education (more than half of each group has received some secondary or tertiary education), and the share of females is comparable (37\% versus $42 \%)$. The household structure, however, differs considerably: undocumented immigrants are more likely to be single (55\% versus $33 \%$ among documented immigrants) and less likely to have children (45\% versus $58 \%$ among documented immigrants). The average size of their household in Italy is smaller (1.4 versus 2.4 members) and those who are married or have children are more likely to have left their

${ }^{24}$ To elicit truthful reporting of legal status, the interviews are anonymous, ask for no sensitive information (e.g., addresses), and are carried out in public spaces by foreign-born interviewers (when possible, from the same country as the interviewees) who emphasize the independence of the ISMU Foundation from any Italian government body. The information on legal status is obtained by asking the immigrants about the type of legal documents they have, starting with the most permanent (being an Italian citizen) and moving down to the option of "no documents". Appendix Table A.2 shows how the question is structured. 
spouse (59\% versus $25 \%$ ) and children ( $84 \%$ versus $38 \%$ ) abroad. The share of unemployed individuals among undocumented immigrants is also twice as high as among documented immigrants (8\% versus 4\%). On average, the undocumented immigrants in our sample have been in Italy for about 2.7 years versus 5.8 years for documented immigrants. The last column in Table 1 shows that most of these differences are statistically different at least at a $5 \%$ significance level.

In the ISMU survey, each interviewee is asked to report average monthly expenditures of their household in Italy for each of the following broad categories: (a) food, clothing, and other basic needs; (b) housing; (c) other items (e.g., transportation, leisure, etc.). Our measure for consumption in the host country is the sum of these three types of consumption expenditure. Immigrants are also asked about the household's average monthly expenditure for remittances and average monthly savings. Our measure for total household income is then computed as the sum of these five items.

Table 2 reports descriptive statistics on consumption and income of documented and undocumented immigrants. As the ISMU survey collects information on total expenditure at the household level, we obtain individual consumption (income) as the ratio between reported household consumption (income) and the number of members of the household residing in Italy (converted into "equalized adults" using the "modified OECD" equivalence scale). ${ }^{25}$ As Table 2 shows, total net monthly household income is higher for documented than for undocumented immigrants (815 versus 710 euros), as is consumption expenditure (581 versus 424 euros) and the share of income attributed to consumption (74\% versus $65 \%$ ).

${ }^{25}$ The "modified OECD scale" is the official Eurostat equivalence scale. It assigns 1 to the first adult household member, 0.5 to each additional adult member and 0.3 to each child. An alternative is the "standard OECD scale" that assigns a value of 1 to the first adult household member, 0.7 to any further adult and 0.5 to each child. Throughout our empirical analysis (see Section 4), we primarily use individual measures of consumption and income obtained using the "modified OECD scale", but we show that our estimates are robust to using the other two alternative scales. 
Decomposing total household consumption into its three subcategories shows that the share of consumption expenditure by documented (undocumented) immigrants is $39 \%(44 \%)$ for food and clothes, $40 \%$ (31\%) for housing, and $21 \%$ (25\%) for "other" consumption goods. The last column in Table 2 shows that all these differences are statistically significant at least at the $5 \%$ level. These descriptive statistics suggest therefore not only that undocumented immigrants consume less than documented immigrants, but also that the composition of consumption expenditure between the two groups differs, with the largest difference in housing expenditure.

\section{Empirical Results}

We now present our estimation results. We first discuss first stage estimates for our instrumental variables (Section 4.1). In Section 4.2, we report OLS and IV estimates of our main consumption equation.

\subsection{First stage estimates}

Rainfall shocks. Table 3 reports the results of Linear Probability Models of current illegal status on log rainfall in the country of origin at the time of migration (with rainfall normalized by the average within-country standard deviation in the sample). ${ }^{26}$ All regressions include a set of "baseline controls" (interview year dummies, country of origin dummies and years since migration) and cluster the standard errors by country of origin. Because we always condition on country of origin dummies, rainfall levels can be interpreted as deviations from the country means. Columns 1-3 show that rainfall shocks at the time of emigration $T$ and in the year before migration $T-1$ are strong predictors of illegal status, whereas shocks in period $T-2$ are not significant once we condition on shocks in $T$ and $T-1$. Further lags of rainfall shocks are even smaller in magnitude and not significant. In column 4, we include individual controls and we regress current illegal status on the mean of rainfall shocks in the immigration year $(T)$

\footnotetext{
${ }^{26}$ Probit regressions provide very similar results.
} 
and previous year $(T-1)$, as well as on rainfall shocks in the origin country at the time of the interview ("current log rainfall"). While the former variable is strongly significant, the latter has no predictive power. Estimates hardly change if we add further household controls and log income in columns 5 and 6 of Table 3 . Columns 7 and 8 show that our results are not sensitive to the particular definition of undocumented immigrants (see Appendix Table A.2).

These results suggest that rainfall-induced income shocks in the year of emigration and the year previous to that, but not in years further back or in the current year, affect illegal status in Italy. According to the estimates in Table 3, a one standard deviation increase in the precipitation level in the year of migration (the year before emigration) leads to a $3.2(1.8)$ percentage point increase in the probability of being an illegal resident in Italy. ${ }^{27}$ These effects are interesting in their own right because they suggest the importance of weather conditions in explaining illegal migration flows.

Not only is the first stage strong, with an F-statistic of about 40, but the estimated coefficient on past rainfall shocks barely changes with the addition of further controls, suggesting that observable individual and household characteristics are hardly correlated with rainfall shocks in $T$ and $T-1$. This suggests that rainfall shocks do not change the composition of the migrant population - something we investigate in more detail in columns 9-11, where we report results from a regression of predetermined personal characteristics at emigration (log age, gender, and education) on rainfall shocks at the time of emigration, years since migration and a set of dummies for interview year and country of origin (standard errors are clustered by country of origin). Estimates suggest no significant relation between weather shocks at the time of emigration and age, gender, or education. ${ }^{28}$ This is in line with the

${ }^{27}$ The standard deviation is computed as the average within country standard deviation across all countries of origin in our sample over the period 1979-2007.

${ }^{28}$ Similarly, for the U.S. Munshi (2003) finds no significant relation between gender, age and education of Mexican migrants and rainfall levels at the time of migration (see his footnote 33). There is evidence that risk aversion is a strong correlate of some observable characteristics: women are found to be more risk averse than 
hypothesis that these shocks, while affecting the probability of illegal status, do not change the overall composition of the pool of immigrants, at least not with respect to some key observables that are typically correlated with risk aversion. ${ }^{29}$

The underlying rationale for our instrument is that rainfall provokes income shocks by affecting agricultural production, thereby temporarily relaxing the liquidity constraints that restrict migration. ${ }^{30}$ Our instrument should thus be stronger in countries with a larger agricultural sector and where the households are more likely to be cash-in-advance constrained. To investigate this conjecture, we rerun our first stage regressions but interact the instrument (log rainfall in time $T$ and $T-1)$ with dummies that identify countries whose GDP (or employment) share in agriculture is, respectively, above the $75^{\text {th }}$ percentile or below the $25^{\text {th }}$ percentile of the distribution of countries in our sample (columns 2 and 4 of Appendix Table A.4). Estimates show that the effect of rainfall in countries with GDP (employment) shares in agriculture above the 75th percentile is about 2 times larger than in the rest of the

men (see, e.g., Borghans et al. 2009), risk aversion is higher among the least educated (Guiso and Paiella 2008) and non-monotonically related to age (see Barsky et al. 1997).

${ }^{29}$ Although these estimates suggest that rainfall shocks do not affect the pool of potential immigrants, in Appendix Section A2.1 we discuss the consequences for the IV estimates when this condition is violated. In particular, we show that if rainfall shocks select low risk averse individuals into the pool of potential migrants, the IV estimates will be upward biased (similarly to OLS), and identify a lower bound (in absolute value) of the effect of being illegal on consumption. The second assumption for our identification strategy is that, conditional on observable characteristics and legal status, rainfall shocks at emigration have no effect on immigrants' current economic decisions either through weather shock persistence or through effects on later behavior. If there is persistence in rainfall shocks, past rainfall shocks would be correlated with current shocks, which in turn would affect behavior. In unreported regressions, however, we find no evidence for any persistence in rainfall shocks.

${ }^{30}$ Other papers that establish a positive relationship between income shocks and migration include Bryan et al. (2014) and Angelucci (2015). Dustmann and Okatenko (2014) show that the likelihood of an intention to migrate increases with wealth in both Africa and Asia. McKenzie and Rapoport (2007) find that the probability of migration is mostly increasing in household resources for households in communities with less developed migration networks, likely to be the case in Italy due to its relatively recent immigration experience. 
countries, although the effect of rainfall remains important also in countries with a smaller agricultural sector; results remain unchanged even when we control for log GDP per capita in the country of origin at the time of migration (columns 3 and 5). In columns 6 and 7 of Appendix Table A.4, we investigate more directly the role played by credit markets. If credit markets are sufficiently developed, potential migrants (or their relatives) should be able to borrow against their future earnings in the destination country (and/or some collateral in the origin country) in order to finance the migration cost. We therefore expect the first stage of our IV estimates to work better in countries with low levels of financial development. Proxying financial market development by using the World Bank's World Development Indicator that estimates the credit provided by the domestic banking sector as a percentage of GDP, ${ }^{31}$ we find that our instrument is stronger in countries that are financially less developed - a finding that further supports our hypothesis that rainfall shocks relax budget constraints that prevent individuals from migrating.

We further test the robustness of our first stage estimates to the exclusion of large countries where our instrument is potentially less precise. After ranking the countries in our sample according to their total land area, we have rerun our regressions and progressively excluded the 10, 20, and 30 largest countries (columns 8-10 of Appendix Table A.4). Estimates remain unaffected. In further robustness checks, we have tested for potential heterogeneity in the effect of rainfall on legal status across different geographical areas, showing that our instrument is relevant in all areas included in our sample (see Appendix Table A.6). ${ }^{32}$ As we

31 Giuliano and Ruiz-Arranz (2009) use this variable as a proxy for financial development. The banking sector includes monetary authorities and deposit money banks, as well as other banking institutions (savings and mortgage loan institutions and building and loan associations) for which data are available. We match each individual in our sample with the average size of the agricultural sector over the period 1995-2007 in their country of origin (irrespective of their year of migration), and with the size of the banking sector in the year of emigration.

32 In Appendix Table A.6, we have estimated the same regression excluding each geographic area of origin at a time (i.e., Sub-Saharan Africa, Eastern Europe, Latin America, Middle East and North Africa, and Asia), with very similar estimates across specifications (see columns 1-6). In column 7, we estimated our first stage regression interacting (log) rainfall with dummies identifying each region in our sample. The estimated coefficients on the 
discuss in Section 4.2.1, our estimates are also not sensitive to the exclusion of major rainfall shocks.

To test the assumption that rainfall shocks generate indeed temporary income shocks in the sending countries, we use World Bank data on agricultural and total income for a panel of almost 100 developing countries over the period 1979-2012 that correspond to the countries included in our main estimation sample (see Appendix Table A.1), and match to them the GPCP data on rainfalls. In columns 1 and 2 of Appendix Table A.5, we report regressions of agricultural income and total income per capita on the log of yearly rainfall, conditioning on country dummies, year dummies and country-specific time trends, and we cluster standard errors at the country level. In both regressions, the estimated coefficient on log rainfall is positive and strongly significant, with a rainfall elasticity of agricultural income and total income of about 0.2 and 0.03 , respectively. Further, to determine whether rainfall affects income through its effect on agricultural output, we regress the log of total income per capita on the log of agriculture output, instrumenting agricultural output with log rainfall. We report OLS and IV estimates in columns 3 and 4 , and the first stage estimate in the second panel in column 4. The agricultural output elasticity of income is about 0.24 , while the first-stage rainfall elasticity of agricultural output is about 0.13 , with all coefficients being statistically significant at the $1 \%$ level. These estimates therefore support our hypothesis that weather-induced positive income shocks may relax credit constraints. ${ }^{33}$

Legalization quotas. In Table 4, we report first stage estimates of the quota instrument. In Panel A, we use our main quota instrument, regressing illegal residence status on the

interaction terms are all positive, similar in magnitude and statistically significant (with the exception of the interaction for Latin America, which is in the same range than the other estimates, but imprecisely estimated).

${ }^{33}$ Other papers find evidence of a positive effect of rainfall on income. For instance, using data from SubSaharan African countries, Brückner and Ciccone (2011) show a rainfall elasticity of total income of about 0.07 . See also Miguel et al. (2004) and Barrios et al. (2010) for qualitatively similar results. 
residuals of the log of total quotas obtained from estimating equation (2) (see Section 2.3). Columns 1-4 gradually add controls, where all specifications condition on both years since arrival in Italy and interview year dummies. Since we eliminate the systematic relationship between time spent in Italy and accumulated quotas, the coefficient on the quota IV captures the variation in accumulated residence permits off the accumulated linear trend. The estimated coefficient on the quota variable is strongly significant, hardly changes across specifications (which suggests that it is orthogonal to individual characteristics), and has the expected negative sign: being "exposed" to larger accumulated deviations of quotas from their linear trend since arrival in Italy reduces the probability of being illegal at interview. In particular, a $1 \%$ increase in the cumulative number of residence permits offered through the quota system since arrival in Italy - corresponding to almost 6 thousand more places with respect to the mean value in the sample - would imply a 0.3 percentage point lower probability of being undocumented. ${ }^{34}$ Overall, estimates in Panel A of Table 4 show that accumulated residence permits off the accumulated linear trend are a strong predictor of current legal status, with an F-statistics of around 60.

In panel B of Table 4, we report first stage estimates from the alternative quota instruments we describe in Section 2.3. We first report results using the difference between actual and "expected" quotas, predicted under the assumption that immigrants have "adaptive" expectations on future quotas. We then report results where we maintain the assumption of "rational" expectations, but we split the instrument between country-reserved quotas and general quotas (see Section 2.3). For the three major sending countries with reserved quotas - Albania, Morocco and Tunisia (see Appendix Table A.3) - we match each migrant with the residuals of the cumulative number of available slots in the national-specific quotas ("countryreserved quotas") since arrival in Italy, while we match migrants from all other countries to the

${ }^{34}$ Our instrument varies by years since arrival in Italy (1-10) and interview year (2004-2007) and we cluster the standard errors accordingly (i.e. 40 clusters). Clustering by country or origin - as in Table 3 - leads to slightly smaller standard errors. 
residuals of the cumulative non-restricted number of quotas ("non country-reserved quotas"). In both cases, the instruments exhibit negative and strongly significant coefficients, confirming the findings in Panel A. Overall, estimates in Table 4 show that the quota system is a strong predictor of legal status, irrespectively of how we construct the instrument.

\subsection{Consumption and IIlegal Residence Status}

\subsubsection{Total consumption}

OLS estimates when regressing the log of individual monthly expenditure for consumption in Italy on illegal residence status and baseline individual controls and household controls are reported in the first two columns of Table 5. Estimates of the illegal status variable are negative and strongly significant (at the $1 \%$ level), suggesting that undocumented immigrants' total consumption is about $25 \%$ lower than that of documented immigrants.

IV estimates that address endogenous selection into legal status are reported in columns 3-12 of Table 5, where columns 3-4 use the rainfall instrument, columns 5-6 use the quota instrument, and columns 7-8 use both rainfall and total quotas instruments. In columns 9-12, we use the alternative quota instruments we discussed before (see Section 2.3). For each set of instruments, odd columns condition only on baseline and individual controls, while even columns add household controls. IV estimates of the coefficient on illegal residence status are all negative, strongly significant and larger in size (about 1.5-2 times larger) than the corresponding OLS estimates reported in columns 1-2 of Table 5. The estimates are remarkably stable across specifications, despite using two very different identification strategies and alternative definitions of the instruments. The estimated coefficient on illegal residence status is between -0.51 and -0.57 , suggesting a $40 \%-45 \%$ lower total consumption of illegal immigrants. One reason for why IV estimates are larger than OLS estimates is that less risk averse individuals tend to select into illegal migration (see Appendix Section A2.1).

The next to last row of Table 5 reports the p-values from the Durbin-Wu-Hausman test, which tests the null hypothesis that the OLS estimator is consistent and efficient against the 
alternative that it is inconsistent, for each of the specifications we report. At the $10 \%$ level we reject the null hypothesis for all but one specification. Further, when illegal residence status is instrumented with more than one instrument (column 7-8 and 11-12), the last row of Table 5 reports the p-value from the Hansen overidentification test. In all cases, we fail to reject the null hypothesis that the instruments are valid (i.e., uncorrelated with the error term).

We report alternative specifications and robustness checks in Table 6 , where we condition on baseline and individual controls. ${ }^{35}$ We report OLS estimates in Panel A, and IV estimates in Panel B. Each row of Panel B refers to a different instrument set. As a reference point, column 1 reports the estimates in the odd columns of Table 5.

We first test the robustness of our results to alternative measures of consumption. In columns 2, we use the standard OECD equivalence scale to calculate individual consumption from household consumption, while in column 3 we simply divide household consumption by the unweighted number of household members in Italy. Our estimates are similar across these different measures of individual consumption. Next, we use the two alternative definitions of undocumented immigrants described in Section 3: columns 4 and 5 report estimates for the more restrictive (IIlegal2) and less restrictive (IIlegal3) definition, respectively. Estimates are again very similar to those of our main specification.

We show in Table 1 that $15 \%$ of the households of legal immigrants in our sample live in their own house, while this is the case for only $1 \%$ of undocumented immigrants. ${ }^{36}$ Our measure of total consumption includes housing expenditure and we always include among the controls a dummy for home ownership. As a robustness check, we rerun our regressions but with all homeowners excluded from the sample, which leaves us with 11,879 observations. As column 6 in Table 6 shows, the estimated coefficients on the illegal residence status are similar to those in Table 5. Finally, we restrict the sample to immigrants who report being the

${ }^{35}$ Conditioning on additional household controls delivers very similar estimates (as shown in Table 5).

${ }^{36}$ In Italy, undocumented immigrants cannot legally buy a house. Some of the undocumented immigrants may however live in a house owned by another member of the household who is a legal resident in Italy. 
only member in their household. For this subsample, consumption and income at the household and at the individual level are the same. Although this restriction more than halves the sample, size and significance of the estimated coefficients are again very similar to those in previous specifications (see column 7 of Table 6).

In Appendix Table A.7, we report OLS (panel A) and IV (Panel B) estimates of our main consumption equation, varying the residence threshold from at most 5 to at most 15 years. The estimates are remarkably stable across different thresholds. In Appendix Table A.8 we test the robustness of our estimates to the exclusion of major rainfall shocks. Again, OLS and IV estimates are hardly affected by imposing these restrictions on our sample, while the rainfall instrument becomes even stronger when extreme rainfall shocks are excluded.

The estimates presented so far suggest that undocumented immigrants consume substantially less than documented immigrants, and that OLS estimation underestimates the difference in consumption between the two groups. This is compatible with illegal immigrants being less risk averse, leading to a bias towards zero in OLS regressions. While the previous results refer to the overall impact of legal status on consumption behavior, one possible channel may be that illegal immigrants have lower incomes, which in turn leads to lower consumption. In fact, Table 2 points at such income differences between the two groups. We now turn to analysis that investigates how much of the difference in consumption can be accounted for by differences in income.

\subsubsection{Consumption and Income}

As we discuss in Section 2.5, one problem with income in a consumption equation is that the same unobservables may affect both variables alike, which may lead to biased estimates. This problem is exacerbated in our case, as we observe income only at the household level, and we do not have a separate measure on wages and hours worked. If legal status and income are correlated then this may lead to biased estimates in the legal status variable if income is included in the consumption equation. To address this problem we use an IV strategy (outlined 
in Section 2.5), using local unemployment rates in the province of residence as instrument for immigrants' income. As income itself may depend on legal status, the first stage equation will include also the two instruments for illegal status.

We report the first stage estimates from regressing log monthly income (obtained by dividing household income by the number of "equalized" adults using the modified OECD scale) on provincial unemployment rates and other controls in Appendix Table A.9. ${ }^{37} \mathrm{We}$ condition on province and year dummies, and gradually add individual and household controls. We also include (the log of) provincial GDP per capita to keep other macro conditions constant. In columns 4-9 of Appendix Table A.9, we include in addition the rainfall and quota instruments (individually and jointly) that we use to instrument illegal residence status. These specifications are precisely the first stage estimates when both residence status and income are treated as endogenous variables in the consumption equation (see Table 7). Estimates in Appendix Table A.9 show that the unemployment rate in the province of residence is a strong predictor of immigrants' income, significant at the $1 \%$ level with an F-statistics of around 10. In terms of magnitude, a one-percentage point increase in unemployment leads to a $5 \%-6 \%$ reduction in immigrants' income. As a benchmark, the unemployment rate was about $3.7 \%$ in the Lombardy region between 2004 and $2007 .{ }^{38}$

We report estimates of the effect of illegal status conditional on income on monthly total consumption in Table 7. When conditioning on income, the OLS estimate decreases (in absolute value) but remains strongly significant (column 1), suggesting that about half of the difference in consumption between legal and illegal immigrants results from illegal immigrants having lower income. The implied income elasticity of consumption is about 0.77 .

${ }^{37}$ Our measure of income captures individual current income. In addition, all our regressions always include individual controls of the respondents (such as age, gender and education), which are potentially better measures of permanent income.

${ }^{38}$ Standard errors are clustered at the province (11) and interview year (2004-2007) level (i.e. 44 clusters), corresponding to the variation of the instrument. 
IV estimates are reported in columns 2-7 of Table 7 . In all these regressions, we treat illegal residence status as endogenous and present estimates using rainfall shocks (columns 2-3), total quotas (columns 4-5), and both (columns 6-7) as instruments. In columns 3, 5 and 7, we further instrument (log) income. When instrumenting only legal status (columns 2, 4 and 6), the estimated coefficient on this latter variable increases (in absolute value) with respect to the OLS coefficient reported in column 1, suggesting that undocumented immigrants consume about $20 \%-25 \%$ less than documented immigrants, conditional on income. However, when instrumenting income as well, the coefficient on illegal status increases, implying now that illegal immigrants' consumption is about $28 \%-32 \%$ lower than that of legal immigrants. Further, the estimated elasticity of consumption to household income drops from 0.7 to 0.4 when the latter variable is instrumented. It is straightforward to show that these estimates are consistent with a situation where more risk averse individuals consume less and also earn less (as they are less entrepreneurial), and income is negatively correlated with illegal status. ${ }^{39}$

To summarize, unconditional on income, IV estimates suggest that undocumented immigrants consume about $40 \%-42 \%$ less than documented immigrants. Part of this reduction in consumption is due to illegal immigrants having lower incomes than legal immigrants. Conditioning on income, and instrumenting both income and legal status, results in an estimated $29 \%$ lower consumption of illegal immigrants.

\subsubsection{Consumption categories}

Our data allow us to disaggregate total consumption into three categories: expenditure for food and clothes; housing expenditure; and other expenditure, such as transportation and leisure (see Section 3). To gain further insight into immigrants' consumption choices, we now

\footnotetext{
${ }^{39}$ We have also constructed a measure of predicted provincial wages as an alternative instrument for income. Results (available upon request) are very similar to those reported where we use local unemployment as an instrument.
} 
use this information to estimate the effect of illegal status on consumption in each of these categories. Results are reported in Table 8, where columns 1-3 refer to food and clothes, columns 4-6 to housing, and columns 7-9 to other consumption. We report estimates conditioning on individual and household controls.

Panel A reports OLS results where the dependent variable is the (log of) monthly consumption for each category. As in previous tables, IV estimates in Panel B of Table 8 refer to different sets of instrumental variables. Overall, IV coefficients are larger in size than OLS coefficients and precisely estimated, showing that undocumented immigrants reduce each type of consumption. However, there is substantial variation across categories. While estimates suggest a $25 \%$ lower expenditure for food and clothing and for "other" consumption goods (which is the residual category), the largest reduction is for housing expenditure (minus $55 \%)$.

The large reduction in housing consumption is interesting, and may have several explanations. First, given the low income of illegal immigrants, which places them below the poverty line in Italy, housing may be the main margin where adjustments can be made. ${ }^{40}$ As illustrated in Appendix Table A.10, a larger share of undocumented immigrants tends to use free accommodation such as homeless shelter (11\% versus $5 \%$ ), sleeps in accommodation provided by the employer (15.3\% versus $5.9 \%$ ), and shares accommodation with immigrants who are not relatives. Only a small proportion (1.3\%) of undocumented immigrants reports living in an owned property compared to $14.9 \%$ of documented immigrants. The large difference in housing expenditure between documented and undocumented immigrants may also reflect constraints on housing consumption, as undocumented immigrants cannot sign a legal rental contract, obtain a mortgage or purchase a flat. Obtaining legal residence status

40 Over the period considered (2004-2007), the absolute poverty line for an individual residing in urban areas in the north of Italy was about 710 euros, while the relative poverty line was 570 euros. The average undocumented immigrant in our sample falls below both thresholds, while the average documented immigrant is just above the relative poverty line. 
would therefore correspond to relaxing these constraints, resulting in an increase in the estimated parameters.

\subsubsection{Does consumption respond to increased uncertainty?}

One interpretation of the findings presented in the previous sections is that documented and undocumented immigrants adjust their consumption behavior to the exposure to different degrees of income risk, meaning that the difference in consumption may be partly due to differences in precautionary savings. To investigate this further, and to provide additional evidence that precautionary motives are at least one channel for the reduction in consumption of illegal immigrants, we now use a different identification strategy, based on varying uncertainty within the group of illegal immigrants. In particular, we use variation in deportation risk across municipalities and over time and investigate whether consumption behavior of illegal (but not of legal) immigrants responds to these changes.

That deportation risks are well recognized by immigrants is illustrated by AmuedoDorantes et al. (2013) who show in the U.S. context that about $50 \%$ of a sample of undocumented returnees to Mexico feared being deported while residing in the U.S., and that such fears were higher when immigrants lived in states that enacted more punitive measures against illegal residents. In Italy, the enforcement intensity in each Italian province is decided at the local level where instructions from the central government are balanced with local necessities and priorities (see Fasani 2010b). Hence, the number of undocumented immigrants deported each year varies not only across, but also within provinces. ${ }^{41}$ Given the unsystematic way in which these changes are imposed, it is unlikely that undocumented

\footnotetext{
${ }^{41}$ Between 2004 and 2006, in the Lombardy region, the average probability of deportation in each year was
} about $2.6 \%$ (with a standard deviation of 1.68 and a within-province standard deviation of 1.15 ), with a minimum value of $0.04 \%$ and a maximum value of $6.76 \%$ (see Table 9 ). Further, over the period considered here, the probability of undocumented immigrants being arrested and being detained for up to 60 days is about 5 times larger than the probability of actually being deported. 
immigrants can predict future levels of enforcement across areas to adjust their province of residence ex ante. Deportation risk, however, become observable once stricter controls are imposed. Immigrants can react by moving to another province, which however is costly as it means leaving job/accommodation/contacts they have in the province of residence. While the most risk averse migrants may move away, others will stay and adjust their consumption accordingly. Hence, if there was self-selection into provinces according to deportation risk, we would expect the more risk averse to move to areas with lower risks of deportation. This would mean that the estimates we report below can be interpreted as a lower bound. It is important to note that, although changes in deportation risk are temporary, they can produce long-lasting effects on future income, as a deportation leads to a substantial decrease in lifetime income. ${ }^{42}$

To make progress, we construct for each province of immigrant residence a measure of deportation risk for the 2004-2006 period. ${ }^{43}$ We then run the same regressions on consumption as in the previous sections but include the probability of deportation in the province of residence as an additional control variable, together with time and province fixed effects and other background characteristics. Therefore, our Diff-in-Diff design uses only the within-province variation in deportation probabilities for identification. ${ }^{44}$

42 In addition to financial losses, migrants deported from a country of the Schengen area - which includes all EU countries except Great Britain and Ireland plus Iceland, Liechtenstein, Norway, and Switzerland - are banned from legal access to any Schengen country for a minimum of five and a maximum of ten years.

43 The Lombardy region is divided into 11 administrative provinces, and the Italian Ministry of Interior reports the number of undocumented immigrants removed every year from each province (see Fasani 2010b for details). Based on the ISMU survey, we compute the stock of undocumented migrants residing in each county in each year. The ratio of these two measures provides a proxy for the annual probability of being deported. Italian provinces do not simply represent administrative entities, but also functional local labor markets. For instance, the highest level of geographical disaggregation of Labor Force Survey statistics provided by the Italian National Institute of Statistics (ISTAT) is at the provincial level (NUT3).

${ }^{44}$ We use the same estimating sample as the one of our main specification, but we omit observations for 2007 because deportation risk measures are missing for that year. 
We report our estimates for illegal immigrants in columns 1-4 of Table 9, while columns 5-8 report those for legal immigrants, who should be unresponsive to these variations. For both groups, we first control only for time and province fixed effects, and then add additional individual and household controls. Estimates show that an increase in deportation risk within provinces is significantly associated with lower consumption for undocumented immigrants, with a one (within province) standard deviation increase in the probability of deportation (about $44 \%$ with respect to the mean) implying a $13 \%$ reduction in consumption (columns $1-4$ ). In contrast, and consistent with our hypothesis, we find no significant effects of deportation probabilities on consumption for legal immigrants (columns 5-8), with point estimates being close to zero. Moreover, estimated coefficients on the deportation probabilities hardly change when additional controls are included, which indicates that deportation risk is uncorrelated with immigrant characteristics, pointing at there being no selection into provinces based on deportation risk.

These findings speak in favor of income risk being an important determinant of illegal immigrants' consumption behavior, and support the hypothesis that precautionary motives are an important reason for illegal immigrants consuming less than legal immigrants.

\section{$5 \quad$ Discussion and Conclusions}

This paper is - to the best of our knowledge - the first analysis of consumption behavior of immigrants. Drawing on unique data for a country that experienced large scale immigration over the past decades, much of it undocumented, we illustrate stark differences in consumption pattern between documented and undocumented immigrants. Using two novel instrumental variable strategies to address the sorting of immigrants into legal status, we speak to an important issue in the policy debate on illegal immigration - the effect of legalization programs on immigrants' consumption behavior.

Our results imply that legalization programs may lead to an increased level of immigrant consumption in the host country, with potentially beneficial effects for both the host country's 
economy and the immigrants' degree of socioeconomic integration. Indeed, our estimates could be cautiously used to provide back-of-the-envelope calculations of how an amnesty that regularizes all undocumented immigrants could increase consumption in Italy. To do so, we would need to assume that our estimated coefficient is an average treatment effect and that a generalized amnesty would not produce general equilibrium effects that could affect that coefficient. In that case, after amnesty, the regularized immigrants would raise their monthly per capita expenditure by about 230 euros ${ }^{45}$ meaning that, based on the latest estimate of the number of undocumented immigrants $(560,000$ in 2010; see Fasani et al. 2013), a legalization of all immigrants in Italy would translate into a total increase in consumption of about 1.5 billion euros, or about $0.1 \%$ of the 2010 Italian GDP.

If we assume that our estimates also apply to the U.S., the per capita increase in monthly consumption after regularization would be around 430 U.S. dollars, based on the 2012 Consumption Expenditure Survey (CEX) data on the expenditures of individuals of Latino or Hispanic origin. ${ }^{46}$ Given an estimate of 11.5 million undocumented immigrants, an amnesty regularizing the legal status of all those immigrants would imply a higher level of expenditures in the U.S. of about 60 billion U.S. dollars; that is, approximately $0.4 \%$ of the nation's 2012 GDP. These calculations suggest that - again, with the caveat that we ignore general equilibrium effects - the expected increase in expenditures after regularization may be substantial, with clear distributional consequences in favor of the host countries.

${ }^{45}$ We compute per capita expenditures using the information on average monthly consumption and average household size of documented immigrants in Table 1 and Table 2.

46 To compute the per capita increase in monthly consumption, we use information from the 2012 CEX on average annual expenditure (42268 U.S. dollars) and size (3.3) of Hispanic or Latino origin households. We compute an average monthly individual expenditure of about 1070 U.S. dollars and assume this is the level of consumption of documented immigrants in the U.S. Note that if the uncertainty associated with illegal status is lower in the U.S. than in Italy (see Section 3) we would expect a smaller effect in the U.S. context. 
Our findings are also important for analysis on the effects of immigration on the host economy more generally. Borjas (2013) highlights the importance of understanding the balance between the impact of immigration on the size of the consumer base for assessment of permanent wage effects. Our analysis suggests that undocumented immigrants lead to a lower expansion of consumption than legal immigrants, which may have important implications for how they impact on the labor market, wages, employment, as well as tax revenue. 


\section{References}

Adler, Robert F., Joel Susskind, George J. Huffman, David T. Bolvin, Eric J. Nelkin, Alfred Chang, Ralph Ferraro, Arnold Gruber, Ping-Ping Xie, John Janowiak, Bruno Rudolf, Udo Schneider, Scott Curtis, and Philip Arkin (2003). "The Version-2 Global Precipitation Climatology Project (GPCP) Monthly Precipitation Analysis (1979-Present)." Journal of Hydrometeorology, 4, 1147-1167.

Amuedo-Dorantes, Catalina, Cynthia Bansak, and Steven Raphael (2007). "Gender Differences in the Labor Market Impact of IRCA." American Economic Review, 97, 412416.

Amuedo-Dorantes, Catalina and Francesca Mazzolari (2010). "Remittances to Latin America from Migrants in the United States: Assessing the Impact of Amnesty Programs." Journal of Development Economics, 91, 323-335.

Amuedo-Dorantes, Catalina, Thitima Puttitanun, and Ana P. Martinez-Donate (2013). "How

Do Tougher Immigration Measures Impact Unauthorized Immigrants?" Demography, $50,1067-1091$.

Angelucci, Manuela (2012). "U.S. Border Enforcement and the Net Flow of Mexican Illegal Migration." Economic Development and Cultural Change, 60, 311-357.

Angelucci, Manuela (2015). "Migration and financial constraints: evidence from Mexico." Review of Economics and Statistics, 97, 224-228.

Barrios, Salvador, Luisito Bertinelli, and Eric Strobl (2010). "Trends in Rainfall and Economic Growth in Africa: A Neglected Cause of the African Growth Tragedy." Review of Economics and Statistics, 92, 350-366.

Barsky, Robert B., F. Thomas Juster, Miles S. Kimball, and Matthew D. Shapiro (1997). "Preference Parameters and Behavioral Heterogeneity: an Experimental Approach in the Health and Retirement Study." Quarterly Journal of Economics, 112, 537-579.

Bazzi, Samuel (2014). "Wealth Heterogeneity and the Income Elasticity of Migration." Working paper, Boston University. 
Bohn, Sarah, Magnus Lofstrom, and Steven Raphael (2014). "Did the 2007 Legal Arizona Workers Act Reduce the State's Unauthorized Immigrant Population?" Review of Economics and Statistics, 96, 258-269.

Borghans, Lex, Bart Golsteyn, James J. Heckman and Huub Meijers (2009). "Gender Differences in Risk Aversion and Ambiguity Aversion." Journal of the European Economic Association, 7, 649-658.

Borjas, George J. (2013). "The analytics of the wage effect of immigration." IZA Journal of Migration, 2:22.

Borjas, George J. and Marta Tienda (1993). "The Employment and Wages of Legalized Immigrants." International Migration Review, 27, 712-747.

Browning, Martin and Annamaria Lusardi (1996). "Household Saving: Micro Theories and Micro Facts." Journal of Economic Literature, 34, 1797-1855.

Brückner, Marcus (2010). "Population Size and Civil Conflict Risk: Is there a Causal Link?" Economic Journal, 120, 535-550.

Brückner, Marcus and Antonio Ciccone (2011). "Rain and the democratic window of opportunity." Econometrica 79, 923-947.

Bryan, Gharad, Shyamal Chowdhury, and Ahmed Mushfiq Mobarak (2014). "Underinvestment in a Profitable Technology: The Case of Seasonal Migration in Bangladesh." Econometrica 82, 1671-1748.

Chassamboulli, Andri and Giovanni Peri (2015). "The Labor Market Effects of Reducing the Number of Illegal Immigrants." Review of Economic Dynamics 18, 792-821.

Chau, Nancy H. (2001). "Strategic Amnesty and Credible Immigration Reform." Journal of Labor Economics, 19, 604-634.

Chiswick, Barry R. (1988). "Illegal immigration and immigration control." Journal of Economic Perspectives, 2, 101-115.

Ciccone, Antonio (2011). "Economic Shocks and Civil Conflict: A Comment." American Economic Journal: Applied Economics, 3, 215-27. 
Del Boca, Daniela and Alessandra Venturini (2003). "Italian Migration." IZA Discussion Paper No. 938.

Dell, Melissa, Benjamin F. Jones, and Benjamin A. Olken (2012). "Temperature Shocks and Economic Growth: Evidence from the Last Half Century." American Economic Journal: Macroeconomics, 4, 66-95.

Deschênes, Olivier and Enrico Moretti (2009). "Extreme Weather Events, Mortality and Migration." Review of Economics and Statistics, 91, 659-681.

Devillanova, Carlo, Francesco Fasani, and Tommaso Frattini (2014). "Employment of Undocumented Immigrants and the Prospect of Legal Status: Evidence from an Amnesty Program", CReAM Discussion Paper 15/14.

Dustmann, Christian (1997). "Return migration, Uncertainty and Precautionary Savings." Journal of Development Economics, 52, 295-316.

Dustmann, Christian, Albrecht Glitz, and Thorsten Vogel (2010). "Employment, wages, and the economic cycle: Differences between immigrants and natives." European Economic Review, 54, 1-17.

Dustmann, Christian and Joseph-Simon Görlach (forthcoming). "The Economics of Temporary Migrations." Journal of Economic Literature.

Dustmann, Christian and Josep Mestres (2010). "Savings, Asset Holdings, and Temporary Migration." Annales d'Economie et de Statistique, 97/98, 289-306.

Dustmann, Christian and Anna Okatenko (2014). "Out-migration, wealth constraints, and the quality of local amenities." Journal of Development Economics, 110(C), 52-63.

Dustmann, Christian, Uta Schönberg, and Jan Stuhler (2015). "Labor Supply Shocks and the Dynamics of Local Wages and Employment." Working paper, University College London.

Dynan, Karen (1993). "How Prudent are Consumers?" Journal of Political Economy, 101, 1104-1113. 
Ethier, Wilfred J. (1986). "Illegal Immigration: the Host-Country Problem." American Economic Review, 76, 56-71.

Facchini, Giovanni and Cecilia Testa (2014). "The rhetoric of closed borders: quotas, lax enforcement and illegal immigration," IZA Discussion Paper No. 8457.

Fasani, Francesco (2010a). “The Quest for “La Dolce Vita”? Undocumented Migration in Italy," in Triandafyllidou A. (edited by) "Irregular Migration in Europe: Myths and Realities," Ashgate.

Fasani, Francesco (2010b). "Deporting Undocumented Immigrants: the Role of Labor Demand Shocks." Working paper, University College London.

Fasani, Francesco (forthcoming). "Understanding the Role of Immigrants' Legal Status: Evidence from Policy Experiments." CESifo Economic Studies.

Fasani, Francesco, Ludovica Gazzè, Paolo Pinotti, and Marco Tonello (2013). "Immigration policy and crime." Report for the XV European Conference, Fondazione Rodolfo Debenedetti.

Feng, Shuaizhang, Alan. B. Krueger, and Michael Oppenheimer (2010). "Linkages among climate change, crop yields and Mexico-U.S. cross-border migration." PNAS, 107 (32) 14257-14262.

Friebel, Guido and Sergei Guriev (2006). "Smuggling Humans: A Theory of Debt-Financed Migration." Journal of the European Economic Association, 4, 1085-1111.

Fuchs-Schündeln, Nicola and Matthias Schündeln (2005). "Precautionary Savings and SelfSelection: Evidence from the German Reunification Experiment." Quarterly Journal of Economics, 120, 1085-1120.

Gathmann, Christina (2008). "Effects of enforcement on illegal markets: Evidence from migrant smuggling along the southwestern border." Journal of Public Economics, 92, 1926-1941. 
Giles, John and Kyeongwon Yoo (2007). "Precautionary Behavior, Migrant Networks and Household Consumption Decisions: An Empirical Analysis Using Household Panel Data from Rural China." Review of Economics and Statistics, 89, 534-551.

Giuliano, Paola and Marta Ruiz-Arranz (2009). "Remittances, Financial Development and Growth." Journal of Development Economics, 90, 144-152.

Gourinchas, Pierre-Olivier and Jonathan A. Parker (2001). "The Empirical Importance of Precautionary Saving." American Economic Review, 91, 406-412.

Goyle, Rajeev and David A. Jaeger (2005). "Deporting the Undocumented: A Cost Assessment." Center for American Progress.

Guiso, Luigi, Tullio Jappelli, and Luigi Pistaferri (2002). "An Empirical Analysis of Earnings and Employment Risk." Journal of Business \& Economic Statistics, 20, 241-53.

Guiso, Luigi and Monica Paiella (2008). "Risk Aversion, Wealth and Background Risk." Journal of the European Economic Association, 6, 1109-1150.

Hanson, Gordon H., (2006). "Illegal Migration from Mexico to the United States." Journal of Economic Literature, 44, 869-924.

Hanson, Gordon H., Raymond Robertson, and Antonio Spilimbergo (2002). "Does Border Enforcement Protect U.S. Workers from Illegal Immigration?" Review of Economics and Statistics, 84, 73-92.

Hanson, Gordon H. and Antonio Spilimbergo (1999). "Illegal Immigration, Border Enforcement and Relative Wages: Evidence from Apprehensions at the U.S.-Mexico Border." American Economic Review, 89, 1337-1357.

Heckman, James J. and Thomas E. MaCurdy (1980). "A life cycle model of female labor supply." Review of Economic Studies, 46, 47-74.

Hotchkiss, Julie L. and Myriam Quispe-Agnoli (2009). "Employer Monopsony Power in the Labor Market for Undocumented Workers." Working Paper 2009-14, Federal Reserve Bank of Atlanta. 
Hubbard, R. Glenn, Jonathan Skinner, and Stephen P. Zeldes (1995). "Precautionary Saving and Social Insurance." Journal of Political Economy, 103, 360-399.

HWWI (2009) "Database on Irregular Migration, Clandestino Project (Undocumented migrants. Counting the Uncountable - Data and Trends across Europe)." Hamburg Institute of International Economics (HWWI), (available at: http://irregularmigration.hwwi.net/Home.2560.0.html).

Jandl, Michael (2004). "The Estimation of Illegal Migration in Europe.” Migration Studies, vol. XLI, No. 153, 141-155.

Kaushal, Neeraj (2006). "Amnesty Programs and the Labor Market Outcomes of Undocumented Workers." Journal of Human Resources, XLI (3), 631-647.

Kossoudji, Sherrie A. and Deborah Cobb-Clark (2002). "Coming Out of the Shadows: Learning about Legal Status and Wages from the Legalized Population." Journal of Labor Economics, 20, 598-628.

Maccini, Sharon and Dean Yang (2009). "Under the Weather: Health, Schooling and Economic Consequences of Early-Life Rainfall." American Economic Review, 99, 10061026.

Mastrobuoni, Giovanni and Paolo Pinotti (2015). "Legal status and the criminal activity of immigrants." American Economic Journal: Applied Economics, 7, 175-206.

McKenzie, David and Hillel Rapoport (2007). "Network effects and the dynamics of migration and inequality: Theory and evidence from Mexico." Journal of Development Economics, $84,1-24$.

Miguel, Edward, Satyanath Shanker, and Ernest Sergenti (2004). "Economic Shocks and Civil Conflict: An Instrumental Variables Approach." Journal of Political Economy, 112, 725753.

Munshi, Kaivan (2003). "Networks in the Modern Economy: Mexican Migrants in the U.S. Labor Market." Quarterly Journal of Economics, 118, 549-597. 
Orrenius, Pia M. and Madeline Zavodny (2005). "Self-selection among undocumented immigrants from Mexico." Journal of Development Economics, 78, 215-240.

Passel, Jeffrey S. and D’Vera Cohn (2008). "Trends in Unauthorized Immigration: Undocumented Inflow Now Trails Legal Inflow." Washington, DC: Pew Hispanic Center. Paxson, Christina (1992). "Using Weather Variability to Estimate the Response of Savings to Transitory Income in Thailand." American Economic Review, 82, 15-33.

Pinotti, Paolo (2015). “Clicking on Heaven's Door: The Effect of Immigrant Legalization on Crime", Working paper, Bocconi University.

Pugatch, Todd and Dean Yang (2010). "The Impact of Mexican Immigration on U.S. Natives: Evidence from Migrant Flows Driven by Rainfall Shocks." Working paper, Oregon State University.

Schneider, Friedrich (2005). "Shadow Economies Around the World: What do we Really Know?" European Journal of Political Economy, 21, 598-642.

Skinner, Jonathan (1988). "Risky income, life cycle consumption, and precautionary savings." Journal of Monetary Economics, 22, 237-255.

The Economist (2012). "The crossing point. Would-be immigrants to Europe can go almost anywhere-for a price", March 3rd 2012.

UNODC (2012). "Smuggling of migrants from the Northern Triangle to the United States." in “Transnational Organized Crime in Central America and the Caribbean”, 45-53.

U.S. Department of Homeland Security (2012). "Estimates of the Unauthorized Immigrant Population Residing in the United States: January 2011." https://www.dhs.gov/xlibrary/assets/statistics/publications/ois_ill_pe_2011.pdf .

Wolpin, Kenneth I. (1982). "A New Test of the Permanent Income Hypothesis: the Impact of Weather on the Income and Consumption of Farm Households in India." International Economic Review 23, 583-594.

Woodland, Alan D. and Chisato Yoshida (2006). "Risk preference, immigration policy and illegal immigration." Journal of Development Economics, 81, 500-513. 
Yang, Dean and HwaJung Choi (2007). "Are Remittances Insurance? Evidence from Rainfall Shocks in the Philippines." World Bank Economic Review, 21, 219-248. 


\section{Tables}

TABLE 1—Documented ANd Undocumented Immigrants: Descriptive Statistics

\begin{tabular}{|c|c|c|c|c|c|c|c|}
\hline & \multirow{2}{*}{\multicolumn{2}{|c|}{ Variable }} & \multicolumn{2}{|c|}{$\begin{array}{l}\text { Documented } \\
\text { immigrants }\end{array}$} & \multicolumn{2}{|c|}{$\begin{array}{l}\text { Undocumented } \\
\text { immigrants }\end{array}$} & \multirow{2}{*}{$\begin{array}{c}\text { significant } \\
\text { difference } \\
(5 \%) \\
\end{array}$} \\
\hline & & & Mean & Std. Dev. & Mean & Std. Dev. & \\
\hline \multirow[t]{10}{*}{ Respondent: } & Age & & 33.32 & 7.64 & 31.60 & 8.50 & * \\
\hline & Female & & 0.42 & 0.49 & 0.37 & 0.48 & * \\
\hline & Education: & none & 0.09 & 0.28 & 0.11 & 0.31 & * \\
\hline & & primary/compulsory & 0.37 & 0.48 & 0.35 & 0.48 & \\
\hline & & secondary & 0.40 & 0.49 & 0.42 & 0.49 & \\
\hline & & tertiary & 0.14 & 0.35 & 0.12 & 0.33 & * \\
\hline & Residence & Italy (years) & 5.81 & 2.44 & 2.68 & 1.78 & * \\
\hline & Unemploye & & 0.04 & 0.20 & 0.08 & 0.27 & * \\
\hline & Single & & 0.33 & 0.47 & 0.55 & 0.50 & * \\
\hline & Children (c & immy) & 0.58 & 0.49 & 0.45 & 0.50 & * \\
\hline \multirow[t]{7}{*}{ Household: } & \# househol & members in Italy & 2.43 & 1.47 & 1.45 & 0.95 & * \\
\hline & spouse abr & ad (if married) & 0.25 & 0.44 & 0.59 & 0.49 & * \\
\hline & children ab & oad (if children>0) & 0.38 & 0.49 & 0.84 & 0.37 & * \\
\hline & \# children & broad (if any) & 1.82 & 0.98 & 1.92 & 1.02 & * \\
\hline & children in & taly (if children>0) & 0.68 & 0.47 & 0.23 & 0.42 & * \\
\hline & \# children & Italy (if any) & 1.76 & 0.89 & 1.40 & 0.64 & * \\
\hline & living in ov & n house in Italy & 0.15 & 0.36 & 0.01 & 0.11 & * \\
\hline \multirow[t]{7}{*}{ Area of origin: } & Subsaharar & Africa & 0.17 & 0.38 & 0.16 & 0.36 & \\
\hline & East Asia (a & I Pacific) & 0.06 & 0.23 & 0.03 & 0.18 & * \\
\hline & Eastern Eur & pe \& Central Asia & 0.27 & 0.44 & 0.36 & 0.48 & * \\
\hline & Latin Amer & & 0.15 & 0.35 & 0.19 & 0.39 & * \\
\hline & Middle Eas & \& North Africa & 0.23 & 0.42 & 0.20 & 0.40 & * \\
\hline & South Asia & & 0.12 & 0.33 & 0.06 & 0.24 & * \\
\hline \multirow{2}{*}{\multicolumn{3}{|c|}{$\begin{array}{c}\text { Observations } \\
\text { Total observations }\end{array}$}} & & 665 & \multicolumn{2}{|c|}{1807} & \\
\hline & & & & & & & \\
\hline \multicolumn{3}{|c|}{ Undocumented immigrants share } & \multicolumn{4}{|c|}{0.13} & \\
\hline
\end{tabular}

Note. * denotes a difference between documented and undocumented immigrants that is significant at least at $5 \%$ level. Sample: immigrants with 1-10 years of residence in Italy. ISMU survey years: 2004-2007. 
TABLE 2-Documented AND Undocumented IMMigrants: Consumption AND INCOME

\begin{tabular}{|c|c|c|c|c|c|c|}
\hline & & \multicolumn{2}{|c|}{$\begin{array}{l}\text { Documented } \\
\text { immigrants }\end{array}$} & \multicolumn{2}{|c|}{$\begin{array}{l}\text { Undocumented } \\
\text { immigrants }\end{array}$} & \multirow{2}{*}{$\begin{array}{c}\text { significant } \\
\text { difference } \\
(5 \%)\end{array}$} \\
\hline & & Mean & Std. Dev. & Mean & Std. Dev. & \\
\hline \multicolumn{7}{|c|}{ Monthly values (euros) } \\
\hline \multirow[t]{4}{*}{ Consumption: } & Total & 581.6 & 267.2 & 424.6 & 243.8 & * \\
\hline & Food \& Clothes & 220.0 & 116.9 & 177.5 & 113.1 & * \\
\hline & Housing & 244.4 & 156.3 & 151.5 & 137.1 & * \\
\hline & Other & 117.3 & 95.5 & 95.6 & 82.5 & * \\
\hline \multirow[t]{2}{*}{ Total Income } & & 815.5 & 376.9 & 710.4 & 339.2 & * \\
\hline & \multicolumn{6}{|c|}{ Share of total income } \\
\hline \multirow[t]{5}{*}{ Consumption: } & Total & 0.74 & 0.22 & 0.65 & 0.27 & * \\
\hline & \multicolumn{6}{|c|}{ Share of total consumption } \\
\hline & Food \& Clothes & 0.39 & 0.14 & 0.44 & 0.20 & * \\
\hline & Housing & 0.40 & 0.17 & 0.31 & 0.21 & * \\
\hline & Other & 0.21 & 0.13 & 0.25 & 0.21 & * \\
\hline
\end{tabular}

Note. * denotes a difference between documented and undocumented immigrants that is significant at least at $5 \%$ level. Sample: immigrants with $1-10$ years of residence in Italy. ISMU survey years: 2004-2007. 
TABLE 3 - ILLEgAL RESIDENCE STATUS AND RAINFALL SHOCKS: FiRSt STAGE REGRESSIONS

\begin{tabular}{|c|c|c|c|c|c|c|c|c|c|c|c|}
\hline & \multicolumn{8}{|c|}{ Alternative definitions of Illegal residence status } & \multicolumn{3}{|c|}{ Demographics characteristics } \\
\hline & \multicolumn{6}{|c|}{ Illegal } & \multirow{2}{*}{$\begin{array}{c}\text { Illegal2 } \\
7\end{array}$} & \multirow{2}{*}{$\begin{array}{c}\text { Illegal3 } \\
8 \\
\end{array}$} & \multirow{2}{*}{$\begin{array}{c}\text { ln (Age) } \\
9 \\
\end{array}$} & \multirow{2}{*}{$\begin{array}{c}\text { Female } \\
10\end{array}$} & \multirow{2}{*}{$\begin{array}{c}\text { Higher } \\
\text { Educatior } \\
11\end{array}$} \\
\hline & 1 & 2 & 3 & 4 & 5 & 6 & & & & & \\
\hline ln (Rainfall (T)) & $\begin{array}{c}0.032^{* * *} \\
{[0.005]}\end{array}$ & $\begin{array}{c}0.030^{* * *} \\
{[0.005]}\end{array}$ & $\begin{array}{c}0.031^{\text {*** }} \\
{[0.005]}\end{array}$ & & & & & & & & \\
\hline ln (Rainfall (T-1)) & & $\begin{array}{c}0.018^{* * *} \\
{[0.005]}\end{array}$ & $\begin{array}{c}0.017^{* * *} \\
{[0.005]}\end{array}$ & & & & & & & & \\
\hline ln (Rainfall (T-2)) & & & $\begin{array}{c}0.006 \\
{[0.004]}\end{array}$ & & & & & & & & \\
\hline ln (Rainfall (T,T-1)) & & & & $\begin{array}{c}0.046^{* * *} \\
{[0.007]}\end{array}$ & $\begin{array}{c}0.046^{* * *} \\
{[0.007]}\end{array}$ & $\begin{array}{c}0.045^{* * *} \\
{[0.007]}\end{array}$ & $\begin{array}{c}0.049^{* * *} \\
{[0.008]}\end{array}$ & $\begin{array}{c}0.039 * * * \\
{[0.007]}\end{array}$ & $\begin{array}{c}0.002 \\
{[0.003]}\end{array}$ & $\begin{array}{l}-0.004 \\
{[0.005]}\end{array}$ & $\begin{array}{c}0.007 \\
{[0.006]}\end{array}$ \\
\hline In (Current Rainfall) & & & & $\begin{array}{l}-0.002 \\
{[0.006]}\end{array}$ & $\begin{array}{l}-0.002 \\
{[0.006]}\end{array}$ & $\begin{array}{l}-0.003 \\
{[0.007]}\end{array}$ & $\begin{array}{c}0.002 \\
{[0.006]}\end{array}$ & $\begin{array}{c}0.005 \\
{[0.008]} \\
\end{array}$ & & & \\
\hline Baseline controls & $\mathrm{X}$ & $X$ & $X$ & $\mathrm{X}$ & $\mathrm{X}$ & $X$ & $\mathrm{X}$ & $\mathrm{X}$ & $X$ & $\mathrm{X}$ & $X$ \\
\hline Individual controls & & & & $x$ & $x$ & $x$ & $x$ & $x$ & & & \\
\hline HH controls & & & & & $x$ & $\mathrm{X}$ & & & & & \\
\hline $\ln ($ income) & & & & & & $\mathrm{X}$ & & & & & \\
\hline Observations & 13,672 & 13,672 & 13,672 & 13,672 & 13,672 & 13,672 & 13,672 & 13,672 & 13,672 & 13,672 & 13,672 \\
\hline R-squared & 0.211 & 0.214 & 0.214 & 0.234 & 0.240 & 0.254 & 0.237 & 0.205 & 0.133 & 0.182 & 0.078 \\
\hline IV: F-stat & 34.46 & 20.93 & 15.18 & 40.15 & 39.49 & 35.55 & 38.51 & 29.32 & 0.31 & 0.45 & 1.40 \\
\hline IV: p-value F-stat & 0.00 & 0.00 & 0.00 & 0.00 & 0.00 & 0.00 & 0.00 & 0.00 & 0.58 & 0.50 & 0.24 \\
\hline
\end{tabular}

Note. This table reports LPM estimates of the "Illegal residence status" dummy (columns 1-8) and of individual characteristics (log age, gender, education; columns 9-11) on rainfall and other controls. The dummy Illegal residence status equals one if the respondent lacks legal status (alternative definitions of illegal residence status are used in columns 7 and 8 ). The variables In (Rainfall) are the logarithm of rainfall in the country of origin (normalized by the average within-country standard deviation) in the year of emigration ( $T$ ), one year before emigration ( $T$-1), two years before emigration (T-2), and averaged over the year of migration and the year before (T, T-1). The variable In (Current Rainfall) is the logarithm of rainfall in the country of origin (normalized by the average withincountry standard deviation) in the year of the interview. Baseline controls include: origin country dummies, year dummies (2004-2007) and number of years of residence in Italy of the respondent. Individual controls include: gender, age, age squared, dummies for education level (none, primary, secondary, tertiary) and dummies for Italian province of residence. HH controls include: number of members in the household living in Italy, a dummy for spouse living abroad, number of children living in Italy and abroad, dummy for home ownership. In (income) is log monthly income. For each column, the table reports the F-statistic (IV: F-stat) and the p-value (IV: $p$-value F-stat) from a joint significance test of the excluded instrument(s). Sample: immigrants with 1-10 years of residence in Italy. ISMU survey years: 2004-2007. Standard errors: robust and clustered by country of origin (103 clusters); *significant at $10 \%$; **significant at $5 \%$; *** significant at $1 \%$. 


\begin{tabular}{|c|c|c|c|c|}
\hline & 1 & 2 & 3 & 4 \\
\hline \multicolumn{5}{|c|}{ Panel A: main quota IV } \\
\hline \multirow[t]{2}{*}{ ln (Total Quotas) } & $-0.309^{* * *}$ & $-0.301^{* * *}$ & $-0.306^{* * *}$ & $-0.294^{\star * *}$ \\
\hline & {$[0.039]$} & [0.039] & {$[0.039]$} & {$[0.038]$} \\
\hline IV: F-stat & 61.32 & 59.72 & 61.69 & 58.59 \\
\hline IV: p-value F-stat & 0.00 & 0.00 & 0.00 & 0.00 \\
\hline \multicolumn{5}{|c|}{$\begin{array}{l}\text { Panel B: alternative quota IVs } \\
\end{array}$} \\
\hline \multirow[t]{2}{*}{ ln (Total Quotas) - "adaptive" expect. } & $-0.118^{* \star *}$ & $-0.114^{* * *}$ & $-0.116^{* * *}$ & $-0.111^{* * *}$ \\
\hline & [0.042] & {$[0.041]$} & [0.041] & [0.039] \\
\hline IV: F-stat & 7.876 & 7.543 & 7.754 & 8.012 \\
\hline IV: p-value F-stat & 0.01 & 0.01 & 0.01 & 0.01 \\
\hline \multirow[t]{2}{*}{ In (Country-Reserved Quotas) } & $-0.324^{* * *}$ & $-0.314^{\star * *}$ & $-0.318^{* * *}$ & $-0.308^{* * *}$ \\
\hline & [0.049] & {$[0.048]$} & {$[0.048]$} & {$[0.047]$} \\
\hline \multirow[t]{2}{*}{ ln (Non Country-Reserved Quotas) } & $-0.149^{* * *}$ & $-0.146^{* * *}$ & $-0.149^{* * *}$ & $-0.140^{* * *}$ \\
\hline & [0.027] & {$[0.026]$} & {$[0.026]$} & [0.026] \\
\hline IV: F-stat & 49.60 & 48.07 & 50.67 & 46.68 \\
\hline IV: p-value F-stat & 0.00 & 0.00 & 0.00 & 0.00 \\
\hline Baseline controls & $\mathrm{X}$ & $\mathrm{X}$ & $\mathrm{X}$ & $\mathrm{X}$ \\
\hline Individual controls & & $x$ & $x$ & $x$ \\
\hline HH controls & & & $x$ & $x$ \\
\hline $\ln$ (income) & & & & $x$ \\
\hline Observations & 13,672 & 13,672 & 13,672 & 13,672 \\
\hline
\end{tabular}

Note. This table reports LPM estimates of the "Illegal residence status" dummy on the quota system instruments. The dummy lllegal residence status equalene if the respondent lacks legal status. In Panel A, we use our main quota instrument, In (Total Quotas), i.e. the residuals of log of total quotas since arrival in Italy after estimating equation 2 ee Section 2.3). In panel B, we use two alternative quota instruments. First, we use the instrument In (Total Quotas) - "adaptive" expect. (as defined in Section 2.3) and we then jointly use the residuals of the total number of residence permits offered through the quota system to citizens of Albania, Morocco and Tunisia (In (Country-Reserved Quotas)) and of the total number of residence permits offered to immigrants of all other nationalities (In (non-Country-Reserved Quotas)). Baseline, individual and HH controls and In (income) are defined as in the note to Table 3. For each regression, the table reports the F-statistic (IV: $F$-stat) and the p-value (IV: $p$-value F-stat) from a joint significance test of the excluded instrument(s). Sample: immigrants with 1-10 years of residence in Italy. ISMU survey years: $2004-2007$. Standard errors: robust and clustered by years since arrival in Italy and year of interview (40 clusters); *significant at $10 \%$; ${ }^{* *}$ significant at $5 \%$; ***significant at $1 \%$. 


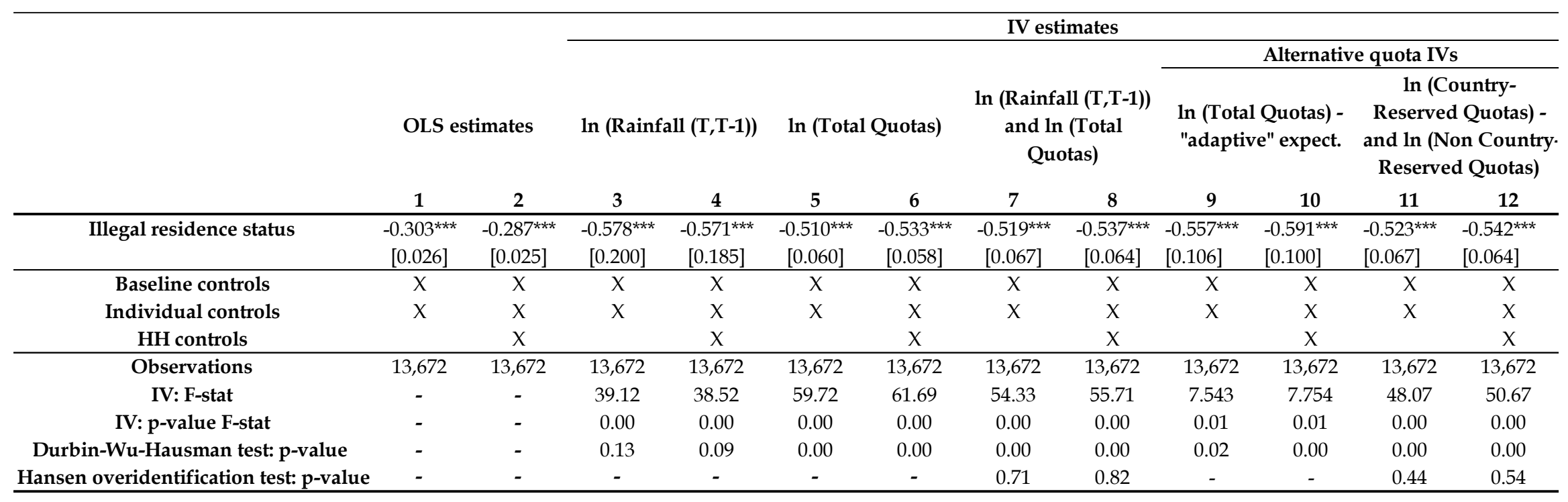

Note. This table reports OLS (columns 1-2) and IV estimates (columns 3-12) of log monthly consumption on illegal residence status and other controls. The dummy IIlegal residence status equals one if the respondent lacks legal status. In columns 3-12 we treat the variable Illegal residence status as endogenous and instrument it with alternative sets of instrumental variables: a) In (Rainfall ( $T$, $T$ 1)) (columns 3-4); b) In (Total Quotas) (columns 5-6); c) In (Rainfall (T, T-1)) and In (Total Quotas) (columns 7-8); d) In (Total Quotas)- "adaptive" expect. (columns 9-10); e) In (Country-Reserved Quotas) and In (non-Country-Reserved Quotas) (columns 11-12). Odd columns condition on baseline and individual controls, while even columns condition also on household controls. Baseline, individual and $\mathrm{HH}$ controls are defined as in the note to Table 3 . For each column, the table reports the F-statistic (IV: F-stat) and the p-value (IV: $p$-value F-stat) from a joint significance test of the excluded instrument(s) and the $p$-value from a regression-based version of the Durbin-Wu-Hausman test for endogeneity (Durbin-Wu-Hausman test: $p$-value). When illegal residence status is instrumented with more than one instrument (columns 7-8 and 11-12) the p-value from the Hansen overidentification test is reported. Sample: immigrants with 1-10 years of residence in Italy. ISMU survey years: 2004-2007. Standard errors: robust and clustered by country of origin (103 clusters); *significant at $10 \%$; **significant at 5\%; ${ }^{* * *}$ significant at $1 \%$. 


\begin{tabular}{|c|c|c|c|c|c|c|c|}
\hline & \multicolumn{3}{|c|}{ Alternative measures of consumption } & \multicolumn{2}{|c|}{$\begin{array}{l}\text { Alternative definitions of Illegal } \\
\text { residence status }\end{array}$} & \multicolumn{2}{|c|}{ Subsamples } \\
\hline & $\begin{array}{l}\text { "Modified" } \\
\text { OECD } \\
\text { equivalence } \\
\text { scale }\end{array}$ & $\begin{array}{c}\text { OECD } \\
\text { equivalence } \\
\text { scale }\end{array}$ & $\begin{array}{c}\text { Unweighted } \\
\text { normalization }\end{array}$ & Illegal2 & Illegal3 & $\begin{array}{c}\text { Excluding } \\
\text { home owners }\end{array}$ & $\begin{array}{c}\text { Only one- } \\
\text { member HHs }\end{array}$ \\
\hline & 1 & 2 & 3 & 4 & 5 & 6 & 7 \\
\hline & \multicolumn{7}{|c|}{ Panel A: OLS estimates } \\
\hline \multirow[t]{3}{*}{ Illegal residence status } & $\begin{array}{c}-0.303^{* * *} \\
{[0.026]}\end{array}$ & $\begin{array}{c}-0.262^{* * *} \\
{[0.027]}\end{array}$ & $\begin{array}{c}-0.203^{* * *} \\
{[0.029]}\end{array}$ & $\begin{array}{c}-0.316^{* * *} \\
{[0.027]}\end{array}$ & $\begin{array}{c}-0.238^{* * *} \\
{[0.025]}\end{array}$ & $\begin{array}{c}-0.285^{* * *} \\
{[0.027]}\end{array}$ & $\begin{array}{c}-0.275^{* * *} \\
{[0.025]}\end{array}$ \\
\hline & \multicolumn{7}{|c|}{ Panel B: IV estimates } \\
\hline & \multicolumn{7}{|c|}{ IV: $\ln ($ Rainfall $(T, T-1))$} \\
\hline \multirow[t]{2}{*}{ Illegal residence status } & $\begin{array}{c}-0.578^{* * *} \\
{[0.200]}\end{array}$ & $\begin{array}{c}-0.633^{* * *} \\
{[0.201]}\end{array}$ & $\begin{array}{c}-0.712 * * * \\
{[0.208]}\end{array}$ & $\begin{array}{c}-0.546^{* * *} \\
{[0.193]}\end{array}$ & $\begin{array}{c}-0.680^{* * *} \\
{[0.240]}\end{array}$ & $\begin{array}{c}-0.571^{* * *} \\
{[0.180]}\end{array}$ & $\begin{array}{c}-0.534^{* * *} \\
{[0.131]}\end{array}$ \\
\hline & \multicolumn{7}{|c|}{ IV: $\ln$ (Total Quotas) } \\
\hline \multirow[t]{2}{*}{ Illegal residence status } & $\begin{array}{c}-0.510^{* * *} \\
{[0.060]}\end{array}$ & $\begin{array}{c}-0.531^{* * *} \\
{[0.062]}\end{array}$ & $\begin{array}{c}-0.570^{* * *} \\
{[0.073]}\end{array}$ & $\begin{array}{c}-0.511^{* * *} \\
{[0.065]}\end{array}$ & $\begin{array}{c}-0.568 * * * \\
{[0.065]}\end{array}$ & $\begin{array}{c}-0.505^{* * *} \\
{[0.065]}\end{array}$ & $\begin{array}{c}-0.543^{* * *} \\
{[0.084]}\end{array}$ \\
\hline & \multicolumn{7}{|c|}{ IV: In (Rainfall (T,T-1)) and $\ln$ (Total Quotas) } \\
\hline Illegal residence status & $\begin{array}{c}-0.519^{* * *} \\
{[0.067]}\end{array}$ & $\begin{array}{c}-0.544^{* * *} \\
{[0.068]}\end{array}$ & $\begin{array}{c}-0.587^{* * *} \\
{[0.076]}\end{array}$ & $\begin{array}{c}-0.516^{* * *} \\
{[0.072]}\end{array}$ & $\begin{array}{c}-0.580^{* * *} \\
{[0.072]}\end{array}$ & $\begin{array}{c}-0.514^{* * *} \\
{[0.068]}\end{array}$ & $\begin{array}{c}-0.541^{* * *} \\
{[0.077]}\end{array}$ \\
\hline Baseline controls & $\mathrm{X}$ & $\mathrm{X}$ & $\mathrm{X}$ & $\mathrm{X}$ & $\mathrm{X}$ & $x$ & $\mathrm{X}$ \\
\hline Individual controls & $x$ & $x$ & $x$ & $X$ & $X$ & $X$ & $x$ \\
\hline Observations & 13,672 & 13,672 & 13,672 & 13,672 & 13,672 & 11,879 & 6,069 \\
\hline
\end{tabular}

Note. This table reports OLS (Panel A) and IV estimates (Panel B) of log monthly consumption on illegal residence status and other controls. The dummy Illegal residence status equals one if the respondent lacks legal status. Each row in Panel B reports IV estimates obtained using a different instrument (set of instruments): a) In (Rainfall (T, $T$-1)); b) In (Total Quotas); c) In (Rainfall (T, $T$-1)) and In (Total Quotas). We perform the following robustness checks: a) we use three alternative definitions of individual consumption, as defined in Section 3.1 (columns 1-3); b) we use two alternative definitions of illegal status, as defined in Appendix Table A.2 (columns 4-5); c) we drop from the main sample all respondents who report to be living in their own house (columns 6); d) we restrict the estimating sample to households with only one member (column 7). Baseline and individual controls are defined as in the note to Table 3. Sample: immigrants with 1-10 years of residence in Italy. ISMU survey years: 2004-2007. Standard errors: robust and clustered by country of origin (103 clusters); *significant at 10\%; **significant at 5\%; *** significant at $1 \%$. 
TABLe 7 - Monthly Consumption - Conditioning on Income: OLS ANd IV estimates

\begin{tabular}{|c|c|c|c|c|c|c|c|}
\hline & \multirow{3}{*}{$\begin{array}{c}\text { OLS } \\
1\end{array}$} & \multicolumn{6}{|c|}{ IV estimates } \\
\hline & & \multicolumn{2}{|c|}{ ln (Rainfall (T,T-1)) } & \multicolumn{2}{|c|}{ ln (Total Quotas) } & \multicolumn{2}{|c|}{$\begin{array}{l}\text { ln (Rainfall (T,T-1)) } \\
\text { and } \ln (\text { Total Quotas }\end{array}$} \\
\hline & & 2 & 3 & 4 & 5 & 6 & 7 \\
\hline Illegal residence status & $\begin{array}{c}-0.132^{* * *} \\
{[0.025]}\end{array}$ & $\begin{array}{c}-0.296^{* *} \\
{[0.132]}\end{array}$ & $\begin{array}{c}-0.394^{* *} \\
{[0.161]}\end{array}$ & $\begin{array}{l}-0.182^{*} \\
{[0.107]}\end{array}$ & $\begin{array}{c}-0.323^{\star *} \\
{[0.141]}\end{array}$ & $\begin{array}{c}-0.196^{* *} \\
{[0.097]}\end{array}$ & $\begin{array}{c}-0.338^{* * *} \\
{[0.128]}\end{array}$ \\
\hline $\ln$ (income) & $\begin{array}{c}0.773^{* * *} \\
{[0.014]}\end{array}$ & $\begin{array}{c}0.757^{* * *} \\
{[0.016]}\end{array}$ & $\begin{array}{c}0.487^{* * *} \\
{[0.177]}\end{array}$ & $\begin{array}{c}0.768^{* * *} \\
{[0.016]}\end{array}$ & $\begin{array}{l}0.458^{* *} \\
{[0.179]}\end{array}$ & $\begin{array}{c}0.766^{* * *} \\
{[0.016]}\end{array}$ & $\begin{array}{l}0.446^{* *} \\
{[0.182]}\end{array}$ \\
\hline & & \multicolumn{6}{|c|}{ Variables instrumented: } \\
\hline Illegal residence status & - & $X$ & $X$ & $\mathrm{X}$ & $\mathrm{X}$ & $X$ & $X$ \\
\hline $\ln$ (income) & - & - & $x$ & - & $x$ & - & $x$ \\
\hline All controls & $\mathrm{X}$ & $X$ & $\mathrm{X}$ & $\mathrm{X}$ & $X$ & $\mathrm{X}$ & $X$ \\
\hline Observations & 13,672 & 13,672 & 13,672 & 13,672 & 13,672 & 13,672 & 13,672 \\
\hline
\end{tabular}

Note. This table reports OLS (columns 1) and IV estimates (columns 2-7) of log monthly consumption on illegal residence status, log monthly income and other controls. The dummy IIlegal residence status equals one if the respondent lacks legal status. In columns 2-7, we treat the variable Illegal residence status as endogenous and instrument it with: a) In (Rainfall ( $T$, $T-1$ )) (columns 2-3); b) In (Total Quotas) (columns 4-5); c) In (Rainfall (T, T-1)) and In (Total Quotas) (columns 6-7). In columns 3, 5 and 7 we instrument In (income) with the unemployment rate in the province of residence. All controls include baseline, individual and HH controls as defined in the note to Table 3. Sample: immigrants with 1-10 years of residence in Italy. ISMU survey years: 2004-2007. Standard errors: robust and clustered by country of origin (103 clusters); ${ }^{*}$ significant at $10 \%$; ${ }^{* *}$ significant at $5 \%$; ${ }^{* * *}$ significant at $1 \%$. 
Table 8 - Monthly Consumption - Consumption Categories: OlS and IV estimates

\begin{tabular}{|c|c|c|c|c|c|c|c|c|c|}
\hline & \multicolumn{3}{|c|}{ Food \& Clothes } & \multicolumn{3}{|c|}{ Housing } & \multicolumn{3}{|c|}{ Other } \\
\hline & 1 & 2 & 3 & 4 & 5 & 6 & 7 & 8 & 9 \\
\hline & \multicolumn{9}{|c|}{ Panel A: OLS estimates } \\
\hline \multirow[t]{3}{*}{ Illegal residence status } & $\begin{array}{c}-0.292^{* * *} \\
{[0.049]}\end{array}$ & $\begin{array}{c}-0.274^{* * *} \\
{[0.044]}\end{array}$ & $\begin{array}{c}-0.130^{* *} \\
{[0.053]}\end{array}$ & $\begin{array}{c}-0.821^{* * *} \\
{[0.085]}\end{array}$ & $\begin{array}{c}-0.748^{* * *} \\
{[0.079]}\end{array}$ & $\begin{array}{c}-0.471^{* * *} \\
{[0.072]}\end{array}$ & $\begin{array}{c}-0.308^{* * *} \\
{[0.045]}\end{array}$ & $\begin{array}{c}-0.314^{* * *} \\
{[0.044]}\end{array}$ & $\begin{array}{c}-0.126^{* * *} \\
{[0.036]}\end{array}$ \\
\hline & \multicolumn{9}{|c|}{ Panel B: IV estimates } \\
\hline & \multicolumn{9}{|c|}{ IV: $\ln$ (Rainfall (T,T-1)) } \\
\hline \multirow[t]{2}{*}{ Illegal residence status } & $\begin{array}{c}-0.721^{* * *} \\
{[0.239]}\end{array}$ & $\begin{array}{c}-0.718^{* * *} \\
{[0.233]}\end{array}$ & $\begin{array}{c}-0.470 * * \\
{[0.191]}\end{array}$ & $\begin{array}{c}-1.610^{* * *} \\
{[0.507]}\end{array}$ & $\begin{array}{c}-1.660^{* * *} \\
{[0.467]}\end{array}$ & $\begin{array}{c}-1.183^{* * *} \\
{[0.450]}\end{array}$ & $\begin{array}{c}-0.612 \\
{[0.387]}\end{array}$ & $\begin{array}{c}-0.567 \\
{[0.380]}\end{array}$ & $\begin{array}{c}-0.228 \\
{[0.282]}\end{array}$ \\
\hline & \multicolumn{9}{|c|}{ IV: $\ln$ (Total Quotas) } \\
\hline \multirow[t]{3}{*}{ Illegal residence status } & $\begin{array}{c}-0.554^{* * *} \\
{[0.098]}\end{array}$ & $\begin{array}{c}-0.573^{* * *} \\
{[0.099]}\end{array}$ & $\begin{array}{c}-0.252^{* *} \\
{[0.124]}\end{array}$ & $\begin{array}{c}-1.227^{* * *} \\
{[0.333]}\end{array}$ & $\begin{array}{c}-1.375^{* * *} \\
{[0.315]}\end{array}$ & $\begin{array}{c}-0.756^{* * *} \\
{[0.291]}\end{array}$ & $\begin{array}{c}-0.777^{* * *} \\
{[0.150]}\end{array}$ & $\begin{array}{c}-0.736^{* * *} \\
{[0.145]}\end{array}$ & $\begin{array}{c}-0.313^{* * *} \\
{[0.119]}\end{array}$ \\
\hline & \multicolumn{9}{|c|}{ IV: $\ln$ (Rainfall (T,T-1)) and ln (Total Quotas) } \\
\hline & $\begin{array}{c}-0.574^{* * *} \\
{[0.098]}\end{array}$ & $\begin{array}{c}-0.590 * * * \\
{[0.100]}\end{array}$ & $\begin{array}{c}-0.278^{* *} \\
{[0.117]}\end{array}$ & $\begin{array}{c}-1.273^{\star * *} \\
{[0.318]}\end{array}$ & $\begin{array}{c}-1.409 * * * \\
{[0.302]}\end{array}$ & $\begin{array}{c}-0.808^{* * *} \\
{[0.272]}\end{array}$ & $\begin{array}{c}-0.757^{* * *} \\
{[0.149]}\end{array}$ & $\begin{array}{c}-0.715^{* * *} \\
{[0.144]}\end{array}$ & $\begin{array}{c}-0.303^{* * *} \\
{[0.110]}\end{array}$ \\
\hline Baseline controls & $\mathrm{X}$ & $\mathrm{X}$ & $\mathrm{X}$ & $\mathrm{X}$ & $\mathrm{X}$ & $\mathrm{X}$ & $\mathrm{X}$ & $\mathrm{X}$ & $\mathrm{X}$ \\
\hline Individual controls & $X$ & $X$ & $X$ & $X$ & $X$ & $X$ & $X$ & $X$ & $X$ \\
\hline HH controls & & $X$ & $x$ & & $X$ & $X$ & & $X$ & $x$ \\
\hline $\ln$ (income) & & & $X$ & & & $X$ & & & $X$ \\
\hline Observations & 13,672 & 13,672 & 13,672 & 13,672 & 13,672 & 13,672 & 13,672 & 13,672 & 13,672 \\
\hline
\end{tabular}

Note. This table reports OLS (Panel A) and IV estimates (Panel B) of log monthly expenditure for three different categories of consumption (food and clothes, columns 1-3; housing, columns 4-6; other, column 7-9) on illegal residence status and other controls. The dummy Illegal residence status equals one if the respondent lacks legal status. Each row in Panel B reports IV estimates obtained using a different instrument (set of instruments): a) In (Rainfall (T, T-1)); b) In (Total Quotas); c) In (Rainfall (T, T-1)) and In (Total Quotas). All these instruments are defined as in the notes to Table 3 and Table 4. Baseline, individual and HH controls and In (income) are defined as in the note to Table 3. Sample: immigrants with 1-10 years of residence in Italy. ISMU survey years: $2004-2007$.

Standard errors: robust and clustered by country of origin (103 clusters); *significant at $10 \%$; ${ }^{* *}$ significant at $5 \%$; ${ }^{* *}$ significant at $1 \%$. 
Table 9-Probability of Deportation and Consumption

\begin{tabular}{|c|c|c|c|c|c|c|c|c|}
\hline & \multicolumn{4}{|c|}{ Undocumented immigrants } & \multicolumn{4}{|c|}{ Documented immigrants } \\
\hline & 1 & 2 & 3 & 4 & 5 & 6 & 7 & 8 \\
\hline Prob. of deportation & $\begin{array}{c}-0.157^{* * *} \\
{[0.036]}\end{array}$ & $\begin{array}{c}-0.115^{* * *} \\
{[0.041]}\end{array}$ & $\begin{array}{c}-0.117^{* * *} \\
{[0.039]}\end{array}$ & $\begin{array}{c}-0.116^{* * *} \\
{[0.032]}\end{array}$ & $\begin{array}{c}-0.012 \\
{[0.015]}\end{array}$ & $\begin{array}{l}-0.012 \\
{[0.014]}\end{array}$ & $\begin{array}{c}-0.012 \\
{[0.014]}\end{array}$ & $\begin{array}{l}-0.010 \\
{[0.006]}\end{array}$ \\
\hline Province and year dummies & $X$ & $\mathrm{X}$ & $X$ & $X$ & $\mathrm{X}$ & $\mathrm{X}$ & $X$ & $X$ \\
\hline Individual controls & & $X$ & $X$ & $X$ & & $X$ & $x$ & $x$ \\
\hline HH controls & & & $x$ & $x$ & & & $x$ & $x$ \\
\hline $\ln$ (income) & & & & $x$ & & & & $x$ \\
\hline Observations & 1,299 & 1,299 & 1,299 & 1,299 & 8,413 & 8,413 & 8,413 & 8,413 \\
\hline R-squared & 0.100 & 0.317 & 0.325 & 0.569 & 0.141 & 0.169 & 0.190 & 0.588 \\
\hline Probability of deportation (\%) & & & Mean & Std Dev & $\begin{array}{l}\text { Within } \\
\text { Std Dev }\end{array}$ & Min & Max & \\
\hline & & & 2.59 & 1.68 & 1.15 & 0.04 & 6.76 & \\
\hline
\end{tabular}

Note. This table reports OLS regression estimates of log of monthly consumption on the probability of deportation in the province of residence and other controls. Province and year dummies include: dummies for Italian province of residence and year dummies (2004-2006). Individual controls include: gender, age, age squared, dummies for education level (none, primary, secondary, tertiary), origin country dummies, number of years of residence in Italy of the respondent. HH controls include: number of members in the household living in Italy, a dummy for spouse living abroad, number of children living in Italy and abroad, dummy for home ownership. Sample: immigrants with 1-10 years of residence in Italy. ISMU survey years: 2004-2006. Standard errors (in brackets): robust and clustered by Italian province of residence (11 provinces) and year of the interview (3 years); *significant at $10 \%$; **significant at $5 \%$; ** significant at $1 \%$. 


\section{A. Appendix}

\section{A1. The ISMU data}

The ISMU data are sampled using an intercept point survey methodology based on the tendency of immigrants to cluster at certain locations (McKenzie and Mistiaen, 2009; Blangiardo, 2008). The first step is to create a list of popular intercept points (e.g., ethnic shops and gatherings, churches, health care facilities) and then to randomly select the meeting points and the migrants who visit them for interview. At each location, interviewees are asked how often they visit any of the other meeting points, which allows ex-post selection probabilities to be computed and added to the sample. The Italian government officially recognized the reliability of this technique in 2005 , when it commissioned and financed survey implementation at the national level, with over 30 thousand immigrants interviewed. See Strozza (2004) for a survey of the different methodologies used to estimate undocumented migrants in the Italian context and Boeri et al. (2015) for a comparison of data sources. Mastrobuoni and Pinotti (2011) and Accetturo and Infante (2010) also use ISMU data.

The ISMU survey provides a representative sample of legal and illegal migrants residing in the Lombardy region, one of Italy's largest ( $8 \%$ of the Italian territory), most populated (9.6 million of inhabitants in 2008 , about $16 \%$ of the Italian population), and wealthiest regions. This area accounts for almost $20 \%$ of the national GDP, with a GDP per capita of about 33 thousand euros in 2008 relative to a national average of 25 thousand. It also has the largest migrant population of both documented ( $23 \%$ of the entire migrant population legally residing in Italy in 2005) and undocumented migrants $(22 \%$ of the amnesty applications in the last regularization process in 2002).

The interview questionnaire contains a variety of questions on individual characteristics (e.g., demographics, educational level, labor market outcomes, legal status) and household characteristics (e.g., number of household members in Italy, family members abroad, housing). Since 2004, it also includes questions about household expenditure, savings and remittances. Most particularly, each interviewee is asked to report average monthly 
expenditures of their household in Italy for each of the following broad categories: (a) food, clothing, and other basic needs; (b) housing; (c) other items (e.g., transportation, leisure, etc.). Our measure for consumption in the host country is the sum of these three types of expenditure. Immigrants are also asked about the household's average monthly expenditure for remittances and average monthly savings. Our measure for total household income is computed as the sum of these five items.

\section{A2. Identification issues}

We now discuss the potential bias in our estimates when using OLS, and how it is addressed by our identification strategies. The underlying (main) mechanism that could lead to biased estimates in OLS regressions is that the two groups of immigrants have different risk attitudes on average. Illegal status implies higher exposure to uncertainty (see our discussion in Section 3), so that sorting leads individuals choosing this option having an average lower risk aversion than individuals who are legally resident in the host country.

In this case, and as risk aversion is not observable, we can rewrite the error term in the consumption equation (1) as $\epsilon_{i t}=\omega r_{i}+u_{i t}$, where $r_{i}$ is the individual-specific degree of risk aversion and $u_{i t}$ is an error term uncorrelated with legal status. If more risk averse individuals consume less at any given level of uncertainty and if undocumented immigrants consume less because of exposure to higher uncertainty, the coefficients $\omega$ and $\beta$ in equation (1) are both negative. As more risk averse individuals are less likely to be undocumented, $\operatorname{Cov}\left(I_{i}, r_{i}\right)<0$. We now derive the OLS bias and discuss potential biases in the IV estimates (Section A2.1). For simplicity, we omit the year subscript $t$ from the notation.

\section{A2.1 OLS bias and Instrument Validity}

For simplicity we ignore the vector of controls $X_{i}$ and consider the regression (where we omit the time index): $C_{i}=\beta I_{i}+e_{i}$.

Assuming $\operatorname{Cov}\left(I_{i}, u_{i}\right)=0$, we obtain 


$$
\operatorname{plim} \beta_{O L S}=\beta+\frac{\omega \operatorname{Cov}(I, r)}{\operatorname{Var}(I)}
$$

Since $\omega<0$ and $\operatorname{Cov}\left(I_{i}, r_{i}\right)<0$, the OLS coefficient will be biased upward. If illegal status affects consumption negatively, $|\beta| \geq\left|\beta_{O L S}\right|$.

Rainfall Shocks: Using rainfall shocks $S$ in the country of origin at the time of migration as an instrument for legal status is based on the assumption that these shocks relax credit constraints and induce more potential migrants in the home country to opt for an illegal migration, which implies that $v(I, S)>0$. As we discuss in Section 2.2, international migration decisions are based on permanent differences in lifetime income. Therefore, temporary rainfall shocks should leave the total pool of potential migrants unaltered, as long as they are uncorrelated over time, which we show to be the case in our data. ${ }^{47}$ As a consequence, the composition of the immigrant population in Italy with respect to observables that are typically correlated with risk aversion should not be correlated with rainfall shocks at emigration, which we demonstrate to be the case in Section 4.1 and Table 3. Thus, if the average risk aversion of the migrant population does not change in response to rainfall shocks $(\operatorname{Cov}(S, r)=0)$, our IV estimator consistently estimates the parameter $\beta$, and $\left|\beta_{2 S L S}\right| \geq\left|\beta_{O L S}\right|$.

We now explore the potential bias of the IV estimator in case that weather shocks change the pool of immigrants towards lower risk aversion. This would imply a negative correlation between rainfall and average risk aversion $(\operatorname{Cov}(S, r)<0)$. Define $\hat{I}_{i}$ as the

\footnotetext{
${ }^{47}$ To test for persistence, we first compute rainfall shocks as deviations of yearly rainfalls from their historical
} mean. We then average rainfall shocks by geographic area using the World Bank classification. This computation produces six time series consisting of yearly observations each, for the years 1994 to 2007 (i.e. the time period between the year of arrival of the first migrants in our estimation sample and the year of the last wave of the survey). We then estimate fifth-order autocorrelations (AC), partial autocorrelations (PAC), and portmanteau (Q) statistics that test for white noise based on a null hypothesis of no autocorrelation up to a certain lag. Both the autocorrelations and the portmanteau statistics suggest that rainfall shocks show no persistence, except for South Asia (these tests are available upon request). Our estimates of the consumption equation are robust to the exclusion of migrants from South Asia. 
predicted values of illegal status obtained by running the first stage regression of illegal status $I_{i}$ on $S_{i}$. The plim of the parameter $\beta$ in the second stage regression $C_{i}=\beta I_{i}+e_{i}$ is then given by:

$$
p \lim \beta_{2 S L S}=\beta+\frac{\operatorname{Cov}(\hat{I}, \varepsilon)}{\operatorname{Var}(\hat{I})}=\beta+\frac{\operatorname{Cov}(\alpha S, \omega r)}{\operatorname{Var}(\alpha S)}=\beta+\frac{\omega \operatorname{Cov}(S, r)}{\alpha \operatorname{Var}(S)}
$$

Since $\omega<0, \operatorname{Cov}(S, r)<0$ and $\alpha=\frac{\operatorname{Cov}\left(I_{i}, S_{i}\right)}{\operatorname{Var}\left(S_{i}\right)}>0$, the IV coefficient will be upward biased, so that $|\beta| \geq\left|\beta_{2 S L S}\right|$. In this case, therefore, the IV estimates will identify a lower bound (in absolute value) of the effect of being undocumented on immigrant consumption, and both OLS and IV would tend to underestimate (in absolute value) the causal effect of illegal status on consumption.

\section{References}

Accetturo, Antonio and Luigi Infante (2010). "Immigrant Earnings in the Italian Labor Market." Giornale degli Economisti, 69, 1-28.

Blangiardo, Gian Carlo (2008). "The Centre Sampling Technique in Surveys on Foreign Migrants. The Balance of a Multi-Year Experience." United Nations Statistical Commission and EUROSTAT. Working paper 12 - 29 February 2008.

Boeri, Tito, Marta De Philippis, Eleonora Patacchini, and Michele Pellizzari (2015). "Immigration, Housing Discrimination and Employment." Economic Journal, 125, 586, F82-F114.

Mastrobuoni, Giovanni and Paolo Pinotti (2011). "Migration Restrictions and Criminal Behavior: Evidence from a Natural Experiment." Working paper, Collegio Carlo Alberto.

McKenzie, David and Johan Mistiaen (2009). "Surveying Migrant Households: A Comparison of Census-Based, Snowball, and Intercept Point Surveys." Journal of The Royal Statistical Society Series A, 172, 339-360.

Strozza, Salvatore (2004). "Estimates of the Illegal Foreigners in Italy: A Review of the Literature." International Migration Review, 38, 309-331. 


\section{Appendix Figures}

FiguRE A.1 - TOTAL CUMULATIVE QUOTAS (IN LOGS) AND YEAR OF ARRIVAL IN ITALY, BY SURVEY WAVE

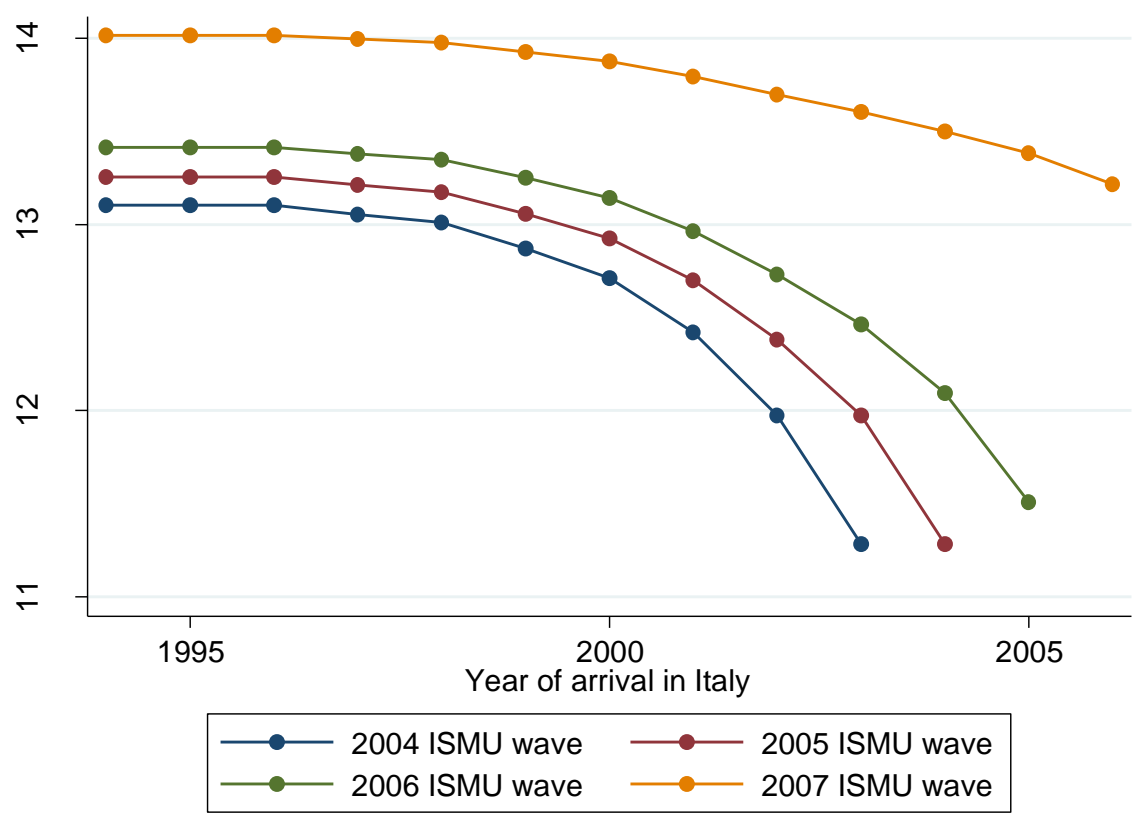

Figure A.2 - Residuals of TOtal CUMULATIVe QUOTAS (IN LOGS) AND YEAR OF ARRIVAL IN ITALY, BY SURVEY WAVE

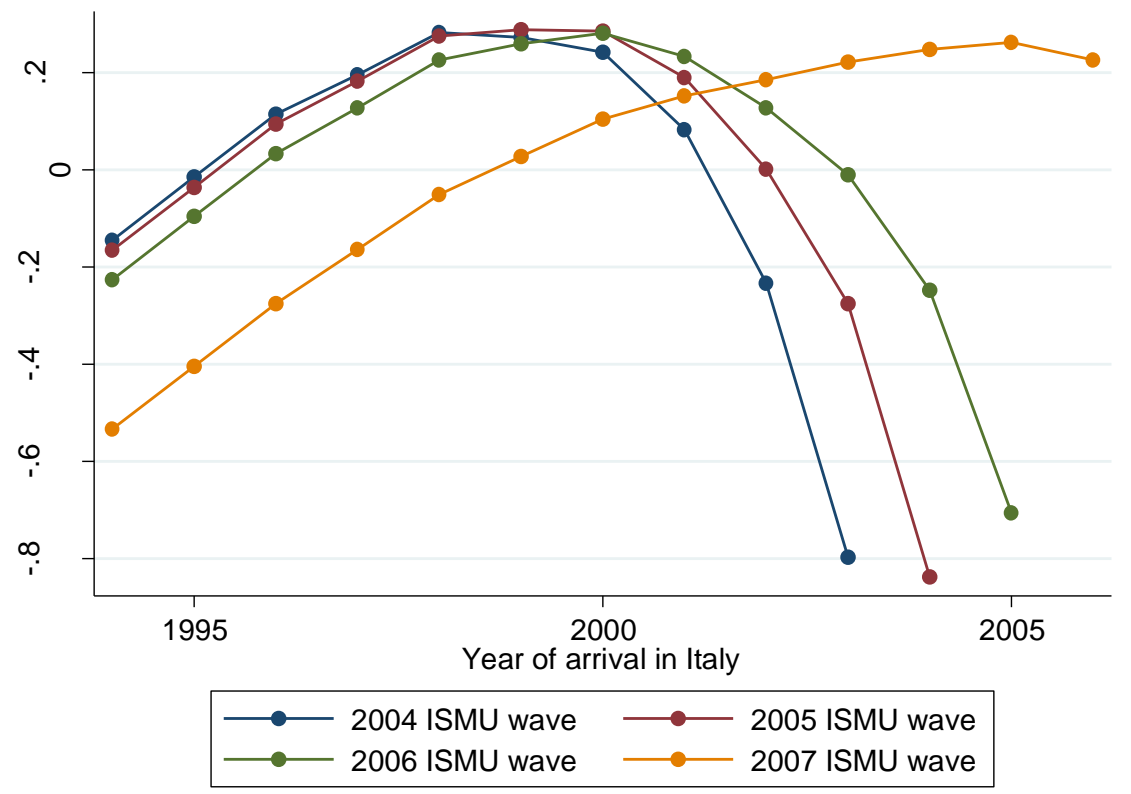

Note. Predicted residuals are obtained from regressing the log of total cumulative quotas on years since migration and four ISMU wave dummies. 


\section{Appendix Tables}

Table A.1 - Countries of Origin, Undocumented Immigrants Shares and Agricultural Sector

\begin{tabular}{|c|c|c|c|c|c|}
\hline \multirow[b]{2}{*}{ Country } & \multicolumn{3}{|c|}{ Sample } & \multicolumn{2}{|c|}{ Agriculture sector (1995-2007) } \\
\hline & Observations & $\begin{array}{c}\text { Share of total } \\
\text { sample }\end{array}$ & $\begin{array}{c}\text { Share of } \\
\text { undocumented } \\
\text { immigrants }\end{array}$ & $\begin{array}{c}\text { Employment } \\
\text { share }\end{array}$ & GDP share \\
\hline MOROCCO & 1576 & 0.12 & 0.10 & 44.88 & 15.83 \\
\hline ALBANIA & 1346 & 0.10 & 0.09 & 66.17 & 30.66 \\
\hline ROMANIA & 874 & 0.06 & 0.22 & 38.18 & 15.52 \\
\hline SENEGAL & 761 & 0.06 & 0.20 & - & 18.76 \\
\hline EGYPT & 682 & 0.05 & 0.20 & 30.06 & 16.54 \\
\hline ECUADOR & 615 & 0.04 & 0.16 & 7.81 & 11.12 \\
\hline PERU & 593 & 0.04 & 0.18 & 4.05 & 8.30 \\
\hline UKRAINE & 579 & 0.04 & 0.29 & 21.47 & 14.12 \\
\hline PAKISTAN & 547 & 0.04 & 0.10 & 45.40 & 24.99 \\
\hline INDIA & 526 & 0.04 & 0.04 & 66.70 & 23.94 \\
\hline TUNISIA & 477 & 0.03 & 0.08 & - & 12.24 \\
\hline CHINA & 447 & 0.03 & 0.08 & 46.64 & 15.60 \\
\hline MOLDOVA & 327 & 0.02 & 0.33 & 46.36 & 26.66 \\
\hline COTE D'IVOIRE & 307 & 0.02 & 0.05 & - & 23.45 \\
\hline PHILIPPINES & 238 & 0.02 & 0.09 & 38.85 & 16.84 \\
\hline SRI LANKA & 235 & 0.02 & 0.08 & 34.74 & 20.29 \\
\hline BRAZIL & 222 & 0.02 & 0.15 & 22.80 & 5.98 \\
\hline NIGERIA & 219 & 0.02 & 0.15 & - & 29.63 \\
\hline BANGLADESH & 209 & 0.02 & 0.08 & 59.00 & 24.07 \\
\hline GHANA & 203 & 0.01 & 0.08 & 55.00 & 36.63 \\
\hline Other 79 nationalities & 2689 & 0.20 & 0.09 & - & - \\
\hline \multirow[t]{4}{*}{ Total } & 13672 & 1.00 & 0.13 & & \\
\hline & \multicolumn{3}{|c|}{ Sample weighted avg (first 20 countries) } & 40.7 & 19.1 \\
\hline & \multicolumn{3}{|c|}{ Italy } & 5.5 & 2.8 \\
\hline & \multicolumn{3}{|c|}{ OECD countries } & 4.2 & 1.9 \\
\hline
\end{tabular}

Note. This table reports the nationality composition of our sample. For each country of origin, we report the number of observations, the share in our estimating sample, and the share of undocumented migrants (columns 1-3). In columns 4-5, we report World Bank data on shares of agricultural employment and GDP. In the last three rows, we report these shares for the first 20 countries in our sample (the average across countries weighted by the number of observations from each country), for Italy, and the average for all OECD countries. 
Table A.2 - Alternative Definitions of Undocumented Immigrants

\begin{tabular}{cccccc}
\hline Current residence status & \multicolumn{5}{c}{ Undocumented immigrants } \\
& obs. & $\%$ & Illegal & Illegal2 & Illegal3 \\
\hline Italian citizenship & 320 & 2.34 & & & \\
Permanent residence permit & 2,022 & 14.79 & & & \\
Temporary residence permit & 8,852 & 64.75 & & & $\mathrm{X}$ \\
No residence permit & 1,697 & 12.41 & $\mathrm{X}$ & $\mathrm{X}$ & $\mathrm{X}$ \\
Applicant for legalization & 110 & 0.8 & $\mathrm{X}$ & & $\mathrm{X}$ \\
Renewing temporary residence permit & 671 & 4.91 & & & 1,697 \\
\hline Total observations & 13672 & 100 & 1,807 & 0.12 & 0.18 \\
Undocumented share & & & 0.13 & & \\
\hline
\end{tabular}

Note. Sample: immigrants with 1-10 years of residence in Italy. ISMU survey years: 2004-2007.

\section{TABLE A.3 - QUOTAS (1996-2007)}

\begin{tabular}{|c|c|c|c|c|c|c|c|c|c|c|c|c|}
\hline & 1996 & 1997 & 1998 & 1999 & 2000 & 2001 & 2002 & 2003 & 2004 & 2005 & 2006 & 2007 \\
\hline Total quotas & 23,000 & 20,000 & 58,000 & 58,000 & 83,000 & 89,400 & 79,500 & 79,500 & 79,500 & 99,500 & 550,000 & 252,000 \\
\hline \multicolumn{13}{|l|}{ of which: } \\
\hline Total non national-reserved quotas & 23,000 & 20,000 & 52,000 & 52,000 & 65,500 & 74,400 & 65,500 & 75,700 & 59,100 & 78,500 & 511,500 & 204,400 \\
\hline Total national-reserved quotas & - & - & 6,000 & 6,000 & 17,500 & 15,000 & 14,000 & 3,800 & 20,400 & 21,000 & 38,500 & 47,600 \\
\hline \multicolumn{13}{|l|}{ of which: } \\
\hline Albania & & & 3,000 & 3,000 & 6,000 & 6,000 & 3,000 & 1,000 & 3,000 & 3,000 & 4,500 & 4,500 \\
\hline Marocco & & & 1,500 & 1,500 & 3,000 & 1,500 & 2,000 & 500 & 2,500 & 2,500 & 4,000 & 4,500 \\
\hline Tunisia & & & 1,500 & 1,500 & 3,000 & 3,000 & 2,000 & 600 & 3,000 & 3,000 & 3,500 & 4,000 \\
\hline Other countries & & & - & - & 5,500 & 4,500 & 7,000 & 1,700 & 11,900 & 12,500 & 26,500 & 34,600 \\
\hline
\end{tabular}

Note. This table reports the size of yearly quotas (total, non-national-reserved and national-reserved) set by the Italian government in the period 1996 to 2007. 
Table A.4 - Illegal Residence Status: Agriculture Sector, Financial Development and Large Countries

\begin{tabular}{|c|c|c|c|c|c|c|c|c|c|c|c|}
\hline \multirow{3}{*}{\multicolumn{2}{|c|}{ Illegal residence status }} & \multirow[b]{3}{*}{1} & \multirow[b]{3}{*}{2} & \multirow[b]{3}{*}{3} & \multirow[b]{3}{*}{4} & \multirow[b]{3}{*}{5} & \multirow[b]{3}{*}{6} & \multirow[b]{3}{*}{7} & \multicolumn{3}{|c|}{ Large countries excluded: } \\
\hline & & & & & & & & & First 10 & First 20 & First 30 \\
\hline & & & & & & & & & 8 & 9 & 10 \\
\hline & Log Rainfall (T,T-1) & $0.046^{\star \star *}$ & $0.044^{\star \star *}$ & $0.041^{* * *}$ & $0.044^{\star * *}$ & $0.040^{\star \star \star}$ & $0.053^{\star \star \star}$ & $0.049^{* \star *}$ & $0.047^{* \star *}$ & $0.048^{* * *}$ & $0.044^{* * *}$ \\
\hline & & {$[0.007]$} & {$[0.008]$} & {$[0.008]$} & [0.009] & [0.009] & [0.007] & {$[0.008]$} & [0.007] & {$[0.008]$} & {$[0.008]$} \\
\hline \multirow[t]{21}{*}{ Log Rainfall (T,T-1): } & * dummy (agriculture GDP share above 75th pct) & & $0.038^{* * *}$ & $0.043^{* * *}$ & & & & & & & \\
\hline & & & [0.012] & {$[0.010]$} & & & & & & & \\
\hline & * dummy (agriculture GDP share below 25th pct) & & -0.016 & -0.008 & & & & & & & \\
\hline & & & {$[0.020]$} & [0.019] & & & & & & & \\
\hline & * dummy (agriculture empl share above 75th pct) & & & & $0.040^{* *}$ & $0.044^{* * *}$ & & & & & \\
\hline & & & & & {$[0.016]$} & {$[0.016]$} & & & & & \\
\hline & * dummy (agriculture empl share below 25th pct) & & & & -0.003 & 0.014 & & & & & \\
\hline & & & & & [0.045] & [0.044] & & & & & \\
\hline & ${ }^{*}$ dummy (banking sector - above 75th pct) & & & & & & $-0.012^{* *}$ & $-0.010^{* *}$ & & & \\
\hline & 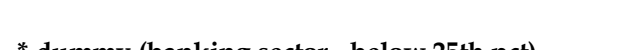 & & & & & & {$[0.005]$} & {$[0.005]$} & & & \\
\hline & ${ }^{*}$ dummy (banking sector - below 25th pct) & & & & & & 0.018 & 0.017 & & & \\
\hline & & & & & & & [0.011] & [0.011] & & & \\
\hline & Current log rainfall & -0.002 & -0.002 & -0.001 & -0.005 & -0.002 & -0.003 & -0.002 & -0.002 & -0.003 & 0.003 \\
\hline & & {$[0.006]$} & {$[0.006]$} & [0.006] & [0.007] & [0.007] & [0.007] & {$[0.007]$} & [0.006] & {$[0.007]$} & [0.005] \\
\hline & Baseline controls & $\mathrm{X}$ & $\mathrm{X}$ & $X$ & $\mathrm{X}$ & $\mathrm{X}$ & $\mathrm{X}$ & $\mathrm{X}$ & $\mathrm{X}$ & $X$ & $\mathrm{X}$ \\
\hline & Individual controls & $\mathrm{x}$ & $\mathrm{x}$ & $\mathrm{x}$ & $\mathrm{x}$ & $\mathrm{x}$ & $\mathrm{X}$ & $\mathrm{X}$ & $\mathrm{x}$ & $\mathrm{x}$ & $x$ \\
\hline & Log GDP per capita (T) & & & $\mathrm{x}$ & & $\mathrm{x}$ & & $x$ & & & \\
\hline & Observations & 13,672 & 13,613 & 13,602 & 11,251 & 11,249 & 13,459 & 13,454 & 12,120 & 11,290 & 9,534 \\
\hline & R-squared & 0.234 & 0.235 & 0.236 & 0.243 & 0.245 & 0.240 & 0.241 & 0.242 & 0.245 & 0.230 \\
\hline & IV: F-stat & 40.15 & 48.29 & 54.76 & 24.20 & 20.80 & 20.36 & 13.00 & 39.60 & 37.36 & 27.20 \\
\hline & IV: p-value F-stat & 0.00 & 0.00 & 0.00 & 0.00 & 0.00 & 0.00 & 0.00 & 0.00 & 0.00 & 0.00 \\
\hline
\end{tabular}

Note. This table reports LPM estimates of the "Illegal residence status" dummy on rainfall and other controls. The dummy Illegal residence status equals one if the respondent lacks legal status. In columns 2-5, Log Rainfall (T, T-1) is interacted with dummies that identify countries whose GDP (employment) share in agriculture is, respectively, above the 75th percentile or below the 25th percentile of the distribution in the countries we have in our sample. In columns 6-7, Log Rainfall (T, T-1) is interacted with dummies that identify countries whose banking sector (as a share of GDP) is, respectively, above the 75th percentile or below the 25th percentile of the distribution in the countries we have in our sample. In columns 3,5 and 7 , we control for the log of real GDP per capita in the country of origin at the time of emigration (Log GDP per capita (T)). In columns 8-10, we exclude immigrants from, respectively, the first 10 , 20 and 30 largest countries in our sample. The countries of origin ranking according to their total land area is: 1) China; 2) Brazil; 3) India; 4) Argentina; 5) Kazakhstan; 6) Sudan; 7) Algeria; 8) Congo, the Democratic Republic; 9) Mexico; 10) Saudi Arabia; 11) Indonesia; 12) Libya; 13) Iran; 14) Peru; 15) Chad; 16) Niger; 17) Angola; 18) Mali; 19) Colombia; 20) Ethiopia; 21) Bolivia; 22) Mauritania; 23) Egypt; 24) Tanzania; 25) Nigeria; 26) Venezuela; 27) Namibia; 28) Pakistan; 29) Mozambique; 30) Turkey. Current Log Rainfall, Baseline controls and Individual controls are defined as in the note to Table 3. For each column, the table reports the F-statistic (IV: F-stat) and the p-value (IV: p-value F-stat) from a joint significance test of the excluded instrument(s). Sample: immigrants with $1-10$ years of residence in Italy. ISMU survey years: 2004-2007. Standard errors: robust and clustered by country of origin (103 clusters); *significant at $10 \%$; ${ }^{* *}$ significant at $5 \%$; ***significant at $1 \%$. 
Table A.5 - Rainfall, Agricultural Output and Income in Developing Countries

\begin{tabular}{|c|c|c|c|c|}
\hline & \multirow{2}{*}{$\begin{array}{c}\text { ln (Agricultural } \\
\text { Income) } \\
\text { OLS }\end{array}$} & \multicolumn{3}{|c|}{ ln (Total Income) } \\
\hline & & OLS & OLS & IV \\
\hline & 1 & 2 & 3 & 4 \\
\hline \multirow[t]{2}{*}{ ln (Rainfall) } & $0.191^{* * *}$ & $0.035^{* *}$ & & \\
\hline & {$[0.036]$} & [0.016] & & \\
\hline \multirow[t]{2}{*}{ In (Agricultural Output) } & & & $0.255^{\star * *}$ & $0.243^{* *}$ \\
\hline & & & {$[0.055]$} & [0.116] \\
\hline \multirow{2}{*}{\multicolumn{2}{|c|}{ First Stage regression - IV: $\ln$ (Rainfall) }} & & & $0.129 * * *$ \\
\hline & & & & {$[0.025]$} \\
\hline Country dummies & $X$ & $X$ & $X$ & $\mathrm{X}$ \\
\hline Year dummies & $X$ & $X$ & $X$ & $X$ \\
\hline Country-specific time trends & $\mathrm{X}$ & $\mathrm{X}$ & $x$ & $\mathrm{X}$ \\
\hline Observations & 2,472 & 2,995 & 2,927 & 2,927 \\
\hline IV: F-stat & - & - & - & 25.75 \\
\hline
\end{tabular}

Note. This table reports estimates of agricultural (column 1) and total income per capita (columns 2-4) on the log of yearly rainfall (columns 1-2) and on log of agricultural output (columns 3-4). In all regressions, we condition on country dummies, year dummies and country-specific time trends. We report OLS estimates in columns 1-3 while in column 4 we report IV estimates obtained by instrumenting log of agricultural output with log of rainfall (First Stage estimates and F-statistics are also reported in column 4). The variables are defined as follows: In (Agricultural Income) is the log of Gross Production Value for crops (constant 2004-2006 million US\$); In (Total Income) is the log of GDP per capita in constant 2005 USD; In (Rainfall) is the log of yearly rainfalls; In (Agricultural Output) is the log of the gross per capita production index number $(2004-2006=100$; the FAO indices of agricultural production show the relative level of the aggregate volume of agricultural production for each year in comparison with the base period 2004-2006: they are based on the sum of price-weighted quantities of different agricultural commodities produced after deductions of quantities used as seed).

Sample: panel data for 97 developing countries (World Bank definition) over the period 1979-2012. Standard errors: robust and clustered by country; *significant at $10 \%$; ** significant at $5 \%$; *** significant at $1 \%$. 


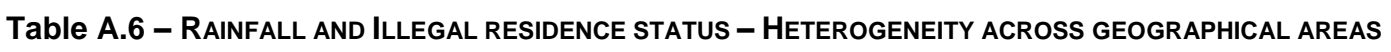

\begin{tabular}{|c|c|c|c|c|c|c|c|}
\hline Illegal residence status & 1 & 2 & 3 & 4 & 5 & 6 & 7 \\
\hline \multirow[t]{2}{*}{ ln Rainfall (T,T-1) } & $0.046^{* * *}$ & $0.039^{* * *}$ & $0.045^{* * *}$ & $0.051^{* * *}$ & $0.048^{* * *}$ & $0.048^{* * *}$ & \\
\hline & [0.007] & [0.007] & {$[0.007]$} & {$[0.012]$} & {$[0.008]$} & {$[0.008]$} & \\
\hline In Rainfall (T, T-1) * Eastern Europe & & & & & & & $\begin{array}{c}0.065^{\star * *} \\
{[0.022]}\end{array}$ \\
\hline In Rainfall $(\mathrm{T}, \mathrm{T}-1) *$ Latin America & & & & & & & $\begin{array}{c}0.052 \\
{[0.040]}\end{array}$ \\
\hline ln Rainfall $(\mathrm{T}, \mathrm{T}-1) *$ North Africa & & & & & & & $\begin{array}{c}0.041^{* * *} \\
{[0.005]}\end{array}$ \\
\hline In Rainfall (T,T-1) * SubSaharan Africa & & & & & & & $\begin{array}{l}0.026^{* *} \\
{[0.011]}\end{array}$ \\
\hline ln Rainfall $(\mathrm{T}, \mathrm{T}-1) *$ Asia & & & & & & & $\begin{array}{l}0.043^{* *} \\
{[0.019]}\end{array}$ \\
\hline Baseline and individual controls & $\mathrm{X}$ & $\bar{X}$ & 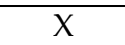 & $\bar{X}$ & $X$ & $\bar{X}$ & $\mathrm{X}$ \\
\hline Observations & 13,672 & 9,809 & 11,572 & 10,734 & 11,339 & 11,234 & 13,672 \\
\hline R-squared & 0.234 & 0.221 & 0.231 & 0.235 & 0.240 & 0.242 & 0.234 \\
\hline IV: F-stat & 40.15 & 35.99 & 37.13 & 18.80 & 36.70 & 39.95 & 16.79 \\
\hline \multirow[t]{2}{*}{ IV: p-value F-stat } & 0.00 & 0.00 & 0.00 & 0.00 & 0.00 & 0.00 & 0.00 \\
\hline & \multicolumn{7}{|c|}{ Geographical areas included: } \\
\hline Eastern Europe - (3863 obs.) & $x$ & & $X$ & $x$ & $X$ & $x$ & $x$ \\
\hline Latin America - (2100 obs.) & $x$ & $x$ & & $x$ & $x$ & $x$ & $x$ \\
\hline North Africa - (2938 obs.) & $x$ & $x$ & $X$ & & $x$ & $x$ & $x$ \\
\hline SubSaharan Africa - (2333 obs.) & $x$ & $x$ & $x$ & $x$ & & $x$ & $x$ \\
\hline Asia - (2438 obs.) & $x$ & $x$ & $x$ & $x$ & $x$ & & $x$ \\
\hline
\end{tabular}

Note. This table reports LPM estimates of the "Illegal residence status" dummy on rainfall and other controls. The dummy Illegal residence status equals one if the respondent lacks legal status. The variable In Rainfall (T, $T$-1) is the logarithm of rainfall in the country of origin (normalized by the average within-country standard deviation) averaged over the year of migration and the year before (T, T-1). In columns 2-6, immigrants from one different geographical area at a time are excluded from the estimating sample. In column 7, we interact the variable In Rainfall ( $T$, $T$-1) with a full set of area dummies. Baseline and individual controls are defined as in the note to Table 3. For each column, the table reports the F-statistic (IV: F-stat) and the p-value (IV: $p$-value F-stat) from a joint significance test of the excluded instrument(s). Sample: immigrants with 1-10 years of residence in Italy. ISMU survey years: 2004-2007. Standard errors: robust and clustered by country of origin (103 clusters); ${ }^{*}$ significant at $10 \%$; ${ }^{* *}$ significant at $5 \%$; ${ }^{* \star}$ significant at $1 \%$. 
Table A.7 - Monthly Consumption - Robustness Checks: Alternative Residence Duration - OLS and IV estimates

\begin{tabular}{|c|c|c|c|c|c|c|c|c|c|c|c|}
\hline & $\begin{array}{c}\mathrm{ysm} \leq 5 \\
1\end{array}$ & $\begin{array}{c}\mathrm{ysm} \leq 6 \\
2\end{array}$ & $\begin{array}{c}y s m \leq 7 \\
3\end{array}$ & $\begin{array}{c}y s m \leq 8 \\
4\end{array}$ & $\begin{array}{c}\text { ysm } \leq 9 \\
5\end{array}$ & $\begin{array}{c}\text { ysm } \leq 10 \\
6\end{array}$ & $\begin{array}{c}\text { ysm } \leq 11 \\
7\end{array}$ & $\begin{array}{c}\text { ysm } \leq 12 \\
8\end{array}$ & $\begin{array}{c}\text { ysm } \leq 13 \\
9\end{array}$ & $\begin{array}{c}\text { ysm } \leq 14 \\
10\end{array}$ & $\begin{array}{c}y s m \leq 15 \\
11\end{array}$ \\
\hline \multirow[b]{2}{*}{ Illegal residence status } & \multicolumn{11}{|c|}{ Panel A: OLS estimates } \\
\hline & $\begin{array}{c}-0.306^{* * *} \\
{[0.028]}\end{array}$ & $\begin{array}{c}-0.299 * * * \\
{[0.027]}\end{array}$ & $\begin{array}{c}-0.299 * * * \\
{[0.026]}\end{array}$ & $\begin{array}{c}-0.300 * * * \\
{[0.026]}\end{array}$ & $\begin{array}{c}-0.300^{* * *} \\
{[0.026]}\end{array}$ & $\begin{array}{c}-0.303^{* * *} \\
{[0.026]}\end{array}$ & $\begin{array}{c}-0.307^{* * *} \\
{[0.026]}\end{array}$ & $\begin{array}{c}-0.310^{* * *} \\
{[0.026]}\end{array}$ & $\begin{array}{l}-0.312^{* * *} \\
{[0.026]}\end{array}$ & $\begin{array}{l}-0.311^{* * *} \\
{[0.026]}\end{array}$ & $\begin{array}{l}-0.313^{* * *} \\
{[0.026]}\end{array}$ \\
\hline & \multicolumn{11}{|c|}{ Panel B: IV estimates [ln (Rainfall (T,T-1)) and ln (Total Quotas)] } \\
\hline Illegal residence status & $\begin{array}{c}-0.465^{* * *} \\
{[0.162]}\end{array}$ & $\begin{array}{c}-0.456^{* * *} \\
{[0.133]}\end{array}$ & $\begin{array}{c}-0.491^{* * *} \\
{[0.121]}\end{array}$ & $\begin{array}{c}-0.498^{\star * *} \\
{[0.089]}\end{array}$ & $\begin{array}{c}-0.501^{* * *} \\
{[0.081]}\end{array}$ & $\begin{array}{c}-0.519 * * * \\
{[0.066]}\end{array}$ & $\begin{array}{c}-0.530^{* * *} \\
{[0.061]}\end{array}$ & $\begin{array}{c}-0.518^{\star * *} \\
{[0.057]}\end{array}$ & $\begin{array}{l}-0.532^{* \star *} \\
{[0.053]}\end{array}$ & $\begin{array}{l}-0.520^{* * *} \\
{[0.051]}\end{array}$ & $\begin{array}{l}-0.535^{\star * *} \\
{[0.048]}\end{array}$ \\
\hline IV: F-stat & 27.27 & 33.74 & 44.13 & 57.52 & 59.46 & 54.33 & 57.78 & 65.87 & 76.29 & 83.23 & 89.07 \\
\hline IV: p-value F-stat & 0.00 & 0.00 & 0.00 & 0.00 & 0.00 & 0.00 & 0.00 & 0.00 & 0.00 & 0.00 & 0.00 \\
\hline Baseline controls & $\mathrm{X}$ & $X$ & $X$ & $\mathrm{X}$ & $X$ & $X$ & $\mathrm{X}$ & $\mathrm{X}$ & $X$ & $X$ & $\mathrm{X}$ \\
\hline Individual controls & $x$ & X & X & X & $\mathrm{X}$ & X & $x$ & $x$ & X & X & X \\
\hline Observations & 7,162 & 8,825 & 10,425 & 11,643 & 12,771 & 13,672 & 14,300 & 14,894 & 15,337 & 15,828 & 16,349 \\
\hline
\end{tabular}

Note. This table reports OLS (Panel A) and IV estimates (Panel B) of log monthly consumption on illegal residence status and other controls. The dummy Illegal residence status equals one if the respondent lacks legal status. In Panel B, illegal residence status is instrumented with In (Rainfall (T, T-1)) and In (Total Quotas). In each column, we restrict the sample to individuals with a maximum duration of residence in Italy of 5 to 15 years. Baseline and individual controls are defined as in the note to Table 3 . For each column, the table reports the F-statistic (IV: F-stat) and the p-value (IV: p-value F-stat) from a joint significance test of the excluded instrument(s). Sample: immigrants with 1-15 years of residence in Italy. ISMU survey years: 2004-2007. Standard errors: robust and clustered by country of origin (103 clusters); *significant at $10 \%$; ${ }^{* *}$ significant at $5 \%$; ${ }^{* *}$ significant at $1 \%$. 
TABle A.8 - Monthly Consumption - Robustness Checks: Excluding Extreme Rainfall Shocks - OLS ANd IV estimates

1

2

3

4

5

6

\begin{tabular}{ccccccc}
\hline & \multirow{2}{*}{ Any shock } & \multicolumn{5}{c}{ Rainfall shocks range: } \\
\cline { 3 - 7 } & & "+/- 2 SD" & "+/- 1.5 SD" & "+/- 1.25 SD" & "+/- 1 SD" & "+/- 0.75 SD" \\
\hline Illegal residence status & $-0.303^{* * *}$ & $-0.304^{* * *}$ & $-0.305^{* * *}$ & $-0.307^{* * *}$ & $-0.304^{* * *}$ & $-0.305^{* * *}$ \\
& {$[0.026]$} & {$[0.026]$} & {$[0.027]$} & {$[0.027]$} & {$[0.029]$} & {$[0.027]$} \\
\hline Illegal residence status & $-0.578^{* * *}$ & $-0.594^{* * *}$ & $-0.492^{* * *}$ & $-0.611^{* * *}$ & $-0.321^{* *}$ & $-0.646^{* * *}$ \\
& {$[0.200]$} & {$[0.204]$} & {$[0.172]$} & {$[0.215]$} & {$[0.143]$} & {$[0.232]$} \\
\cline { 2 - 7 } IV: F-stat & 39.12 & 39.56 & 50.26 & 24.01 & 17.71 & 5.255 \\
\hline Baseline controls & $\mathrm{X}$ & $\mathrm{X}$ & $\mathrm{X}$ & $\mathrm{X}$ & $\mathrm{X}$ & $\mathrm{X}$ \\
Individual controls & $\mathrm{X}$ & $\mathrm{X}$ & $\mathrm{X}$ & $\mathrm{X}$ & $\mathrm{X}$ & $\mathrm{X}$ \\
\hline Observations & 13,672 & 13,656 & 13,236 & 12,558 & 11,477 & 9,505 \\
\hline
\end{tabular}

Note. This table reports OLS (Panel A) and IV estimates (Panel B) of log monthly consumption on illegal residence status and other controls. The dummy Illegal residence status equals one if the respondent lacks legal status. In Panel B, illegal residence status is instrumented with In (Rainfall (T, T-1)). We use the full sample in column 1, while in columns 2-6 we restrict the range of rainfall shocks to $+/-2,+/-1.5,+/-1.25,+/-1$ and $+/-0.75$ standard deviations above/below the country historical mean, respectively. Baseline and individual controls are defined as in the note to Table 3 . For each column, the table reports the F-statistic (IV: F-stat) from a joint significance test of the excluded instrument. Sample: immigrants with 1-10 years of residence in Italy. ISMU survey years: 2004-2007. Standard errors: robust and clustered by country of origin (103 clusters); *significant at $10 \%$; ** significant at $5 \%$; ${ }^{* *}$ significant at $1 \%$. 
TABLE A.9 - Monthly Income: First StAge Estimates

\begin{tabular}{|c|c|c|c|c|c|c|c|c|c|}
\hline & 1 & 2 & 3 & 4 & 5 & 6 & 7 & 8 & 9 \\
\hline unemployment rate & $\begin{array}{c}-0.051^{* * *} \\
{[0.017]}\end{array}$ & $\begin{array}{c}-0.057^{* * *} \\
{[0.017]}\end{array}$ & $\begin{array}{c}-0.056^{* * *} \\
{[0.018]}\end{array}$ & $\begin{array}{c}-0.057^{* * *} \\
{[0.017]}\end{array}$ & $\begin{array}{c}-0.056^{* * *} \\
{[0.018]}\end{array}$ & $\begin{array}{c}-0.059 * * * \\
{[0.018]}\end{array}$ & $\begin{array}{c}-0.058^{* * *} \\
{[0.019]}\end{array}$ & $\begin{array}{c}-0.059 * * * \\
{[0.018]}\end{array}$ & $\begin{array}{c}-0.058^{* * *} \\
{[0.019]}\end{array}$ \\
\hline Baseline controls & $\mathrm{X}$ & $\mathrm{X}$ & $\mathrm{X}$ & $X$ & $\mathrm{X}$ & $\mathrm{X}$ & $\mathrm{X}$ & $X$ & $\mathrm{X}$ \\
\hline Individual controls & $X$ & $X$ & $X$ & $X$ & $X$ & $X$ & $X$ & $X$ & $X$ \\
\hline HH controls & & $x$ & $x$ & $x$ & $x$ & $X$ & $x$ & $x$ & $x$ \\
\hline $\ln ($ GDP per capita) & & & $X$ & & $X$ & & $X$ & & $X$ \\
\hline & \multicolumn{9}{|c|}{ Instruments for Illegal residence status included: } \\
\hline ln (Rainfall (T,T-1)) & - & - & - & $\mathrm{X}$ & $\mathrm{X}$ & - & - & $X$ & $\mathrm{X}$ \\
\hline ln (Total Quotas) & - & - & - & - & - & $X$ & $\mathrm{X}$ & $X$ & $X$ \\
\hline Observations & 13,672 & 13,672 & 13,672 & 13,672 & 13,672 & 13,672 & 13,672 & 13,672 & 13,672 \\
\hline R-squared & 0.127 & 0.180 & 0.180 & 0.181 & 0.181 & 0.185 & 0.185 & 0.186 & 0.186 \\
\hline IV: F-stat & 8.97 & 10.82 & 9.474 & 10.73 & 9.402 & 10.86 & 9.63 & 10.82 & 9.59 \\
\hline IV: p-value F-stat & 0.00 & 0.00 & 0.00 & 0.00 & 0.00 & 0.00 & 0.00 & 0.00 & 0.00 \\
\hline
\end{tabular}

Note. This table reports OLS estimates of log monthly income on unemployment rate in the province of residence and other controls. Baseline, individual and $H H$ controls are defined as in the note to Table 3. In (GDP per capita) is the log of GDP per capita in the province of residence. In columns 4-9, we include the following instruments for illegal residence status: In (Rainfall ( $T$, $T$-1)) (columns 4 and 5); In (Total Quotas) (columns 6 and 7); In Rainfall (T, T-1) and In (Total Quotas) (columns 8 and 9). For each column, the table reports the F-statistic (IV: F-stat) and the p-value (IV: $p$-value Fstat) from a joint significance test of the excluded instrument(s). Sample: immigrants with 1-10 years of residence in Italy. ISMU survey years: 2004-2007. Standard errors: robust and clustered by province of residence and interview year (44 clusters); ${ }^{*}$ significant at $10 \%$; ${ }^{* *}$ significant at $5 \%$; ${ }^{* *}$ significant at $1 \%$. 
Table A.10 - Type Of Accommodation AND Legal Status

\begin{tabular}{lcc}
\hline & $\begin{array}{c}\text { Documented } \\
\text { immigrants }\end{array}$ & $\begin{array}{c}\text { Undocumented } \\
\text { immigrants }\end{array}$ \\
\hline owned property & 14.91 & 1.33 \\
rented flat: with relatives or alone & 53.25 & 22.14 \\
rented flat: with other immigrants & 20.24 & 45.43 \\
free accommodation (guest c/o relatives; homeless shelter, etc.) & 5.03 & 11.07 \\
c/o employer & 5.98 & 15.33 \\
irregular accomodation (squatting, sleeping rough, etc.) & 0.28 & 4.43 \\
other (hotel/hostal) & 0.3 & 0.28 \\
\hline & 100 & 100 \\
\hline
\end{tabular}

Note. This table reports the share of immigrants in each type of accommodation, by legal status. Sample: immigrants with 1-10 years of residence in Italy. ISMU survey years: 2004-2007. 